\title{
An experimental and kinetic modelling study of n-butyl formate combustion
}

Stijn Vranckx ${ }^{\text {a,e, }, \text { Joachim Beeckmann }}{ }^{\text {b }}$, Wassja A. Kopp ${ }^{\text {c }}$, Changyoul Lee ${ }^{\text {a }}$, Liming Cai ${ }^{b}$, Harish K. Chakravarty ${ }^{a}$, Herbert Olivier ${ }^{d}$, Kai Leonhard ${ }^{c}$, Heinz Pitsch ${ }^{\mathrm{b}}$, Ravi X. Fernandes ${ }^{\mathrm{a}, *}$

${ }^{a}$ Physico Chemical Fundamentals of Combustion (PCFC), RWTH Aachen University, Templergraben 55, 52056 Aachen, Germany

${ }^{\mathrm{b}}$ Institute for Combustion Technology (ITV), RWTH Aachen University, Templergraben 55, 52056 Aachen, Germany

${ }^{\mathrm{c}}$ Technical Thermodynamics (LTT), RWTH Aachen University, Templergraben 55, 52056 Aachen, Germany

${ }^{\mathrm{d}}$ Shock Wave Laboratory, RWTH Aachen University, Templergraben 55, 52056 Aachen, Germany

${ }^{\mathrm{e}}$ Flemish Institute for Technological Research (VITO), Boeretang 200, B-2400 Mol, Belgium

* Corresponding authors:

email-address: stijn.vranckx@,vito.be and fernandes@swl.rwth-aachen.de (R.X. Fernandes). tel.: +49 2418026409 (R.X. Fernandes)

address: Physico Chemical Fundamentals of Combustion (PCFC), RWTH Aachen University, Templergraben 55, 52056 Aachen, Germany

Type of article: Full-length article

Shortened running title: n-Butyl formate combustion study
Abstract
The oxidation of n-butyl formate, a potential biofuel candidate, is studied using three different experimental approaches. Ignition delay times have been measured for stoichiometric mixtures of fuel and air for pressures of about 20 and 90 bar at temperatures from 846 up to $1205 \mathrm{~K}$ in a high-pressure shock tube. A rapid compression machine has been used to determine the low-temperature ignition delay times for stoichiometric mixtures at pressures close to 20 bar over the temperature range from $646 \mathrm{~K}$ up to $861 \mathrm{~K}$. Laminar burning velocities have been determined for stoichiometric ratios ranging from $0.8-1.2$ using the 
high-pressure chamber method combined with an optical Schlieren cinematography setup in order to acquire experimental data at elevated pressures of about 10 bar and a temperature of 373 K. A detailed kinetic model has been constructed including high-temperature and lowtemperature reaction pathways. The enthalpies of formation, entropies, and specific heats at constant pressure for the fuel, its primary radicals, and several combustion intermediates have been computed with the CBS-QB3 methods and included in the mechanism. This model was validated successfully against the presented data and used to elucidate the combustion of this interesting ester. The importance of accurate inclusion of the low-temperature peroxy chemistry has been highlighted through sensitivity and reaction path analysis. This study presents the first combustion study of n-butyl formate and leads to an improved understanding of the chemical kinetics of alkyl ester oxidation.

Keywords: n-butyl formate; ester combustion; chemical kinetic modelling; ignition delays; laminar burning velocities;

\section{Introduction}

The need for more environmentally friendly energy sources and the limited fossil resources encourage current research to convert biomass into renewable products. Next-generation production of biofuels from lignocellulosic biomass is a topic of intense research and a range of oxygenated compounds is being proposed as future fuels or components for fuel blends [13]. Molecules containing an ester functional group form an interesting fuel class, depending on the price at which these molecules with reduced sooting tendencies can be produced. Long alkyl chain esters are accessible from vegetable and other oils and are important firstgeneration biofuels which are already adding to the current fuel stream. New secondgeneration methods have recently been proposed to produce esters efficiently from biomass [4]. The oxygen atoms of the ester functional group reduce soot production from the combustion of the fuel, which is another attractive feature [2]. Also, ester fuels are known to perform well in diesel and compression ignition engines and are thus proposed to replace or be blended with conventional diesel.

So far, most combustion studies of esters have focused on methyl esters, which make up most of the current biodiesel fuel molecules [5]. Practical biodiesel fuel molecules are long straight 
chain ester molecules containing up to 18 carbon atoms and having up to 3 double bonds in the chain. The variety in fuel molecules, their high boiling points, and low vapour pressures make fundamental experimental studies of their combustion behaviour difficult. To study the influence of the ester functional group, small molecules like methyl formate and ethyl formate have been studied [6-8]. Both experimental validation data and detailed kinetic mechanisms have been presented for them.

n-Butyl formate has been proposed as a next generation biofuel candidate, further studies on efficient production pathways are currently ongoing within the cluster of excellence on tailormade fuels in Aachen, Germany. The goal of the present study was to investigate and describe the combustion of n-butyl formate, an example of an intermediate alkyl chain ester. For this purpose we have jointly performed kinetic model development with detailed experimental ignition and laminar burning velocity studies. Only very few studies have addressed this molecule. These have focused on its use, for instance, in paints and as solvent, and its relevance as an atmospheric pollutant if used as a fuel [9;10]. The present study therefore presents the first theoretical studies using high-level of theory methods to compute crucial reactions of this fuel's oxidation at combustion relevant temperatures. Further, calculations of the enthalpies of formation, entropies and specific heats for the fuel and several of its oxidation intermediates are included.

Besides the value of this study for characterizing the combustion of this biofuel candidate, it adds to a better understanding of the combustion of other alkyl ester fuels. A kinetic mechanism for intermediate length alkyl esters will prove highly useful in the construction of detailed combustion mechanisms of longer chain esters.

\section{Experimental}

The experiments have been performed in three facilities coupled to different detection techniques. The ignition delay time experiments have been performed in two different experimental devices, a high pressure shock tube (HPST) and a rapid compression machine (RCM) to cover wide temperature ranges. Laminar burning velocities are determined using a closed-vessel combustion chamber combined with an optical Schlieren cinematography set up.

\subsection{High Pressure Shock Tube (HPST)}


The ignition delay time measurements for the intermediate temperature regime have been performed in a heated high-pressure shock tube. The shock tube design, with a constant inner diameter of $140 \mathrm{~mm}$, enables maximum working pressures of up to $1000 \mathrm{bar}$, allowing experiments for compressed gas pressures prior to ignition close to 100 bar. The shock tube consists of a $4 \mathrm{~m}$ driver section separated from an $11 \mathrm{~m}$ driven section with a diaphragm chamber, which houses two stainless steel diaphragms of $3 \mathrm{~mm}$ thickness scored to obtain the desired pressure behind the reflected shock waves. All the experimental results have been obtained with the reflected shock technique under the condition of a tailored interface. This makes it possible to measure relatively long ignition delay times of up to $5 \mathrm{~ms}$. The temperature and pressure behind the reflected shock wave have been calculated from the incident shock velocity, the initial temperature, and filling pressure in the driven section. The incident shock velocity was measured using six piezoelectric pressure sensors (Kistler 603B, $601 \mathrm{H}$ and 6005) mounted at 10, 260, 510, 1010, 1510 and $2510 \mathrm{~mm}$ from the end wall of the driven section. The uncertainty of the experimental temperatures behind the reflected shock waves has been calculated from the estimated uncertainties in the measured shock velocity and the initial temperature, and is close to $\pm 10 \mathrm{~K}$ [11-13]. The calculated heat capacity values needed for the gamma coefficients to calculate the temperatures behind reflected shocks are for n-butyl formate given in table 1. The butyl formate/air mixtures have been prepared directly in the driven section of the shock tube. The fuel (n-butyl formate, Sigma Aldrich, > 97\%) was injected into the evacuated driven section. After evaporation, the synthetic air (Westfalen, $20.5 \% \mathrm{O}_{2}, 79.5 \% \mathrm{~N}_{2}$ ) was added manometrically to obtain the desired equivalence ratio with typical mixture homogenization times of about an hour. Ignition was monitored by the reflected shock pressure and $\mathrm{CH}^{*}$ emission. The reflected shock pressure was traced by a piezoelectric pressure sensor located $10 \mathrm{~mm}$ from the end wall of the shock tube. $\mathrm{CH}^{*}$ emission with the wavelength $430 \mathrm{~nm}$ was obtained with a photomultiplier tube (Hamamatsu, R212UH) through a narrow band pass filter (LOT 430FS10, FWHM 10 +/- 2 nm).

The ignition delay time is defined as the time difference between the arrival of the incident shock at the end wall and the ignition event recorded by an abrupt pressure rise, which is coincident to the $\mathrm{CH}^{*}$ emission rise signal. The difference in the measured ignition delay time of both detection techniques is less than $3 \%$. Throughout this paper the reported values are obtained from the measured pressure profiles and therefore the simulated ignition delay times are based on the pressure increases as well. 


\subsection{Rapid Compression Machine}

The ignition delay times for butyl formate at low-to-intermediate temperatures have been measured using a rapid compression machine (RCM). Fig. 1 gives a schematic of the high pressure RCM used in this study. It can be divided in three major sections; the reactor chamber, the hydraulic section and the pneumatic driver section. The maximum static working pressure for the RCM of 2000 bar makes it possible to work with pressures up to 100 bar in the combustion chamber at the end of compression. For all experiments, the compression stroke is $241 \mathrm{~mm}$, into a cylindrical chamber of $50 \mathrm{~mm}$ diameter, giving a clearance at top dead center of $8 \mathrm{~mm}$ corresponding to a compression ratio of 31.1. Clearance and stroke can be varied by using specially constructed threading. The temperature of the compressed mixture at constant compressed pressure is varied by changing initial temperature $\left(T_{0}\right)$, initial pressure $\left(P_{0}\right)$ and by altering the specific heat of reacting mixture. The latter can be achieved by varying the composition of inert gases $\left(\mathrm{Ar} / \mathrm{N}_{2}\right)$ in the reacting mixture. The reaction chamber is equipped with 6 measuring ports with sensing devices for measuring pressure and temperature, and a gas inlet/outlet port to prepare the reactive mixture. The gas manifold, fuel tank and reaction chamber can all be heated and are temperature-controlled. The reaction chamber is fitted with a Kistler 603B dynamic pressure transducer to measure the pressure in the reaction chamber during the compression and any post-compression event including ignition.

The gas inlet/outlet lines and fuel tanks are evacuated before introducing the mixture components. The vacuum pressures as well as the partial pressures of the vaporized fuels are checked using pressure sensors STS 105112 (range 0 - 500 mbar) with an accuracy of $10^{-4}$ bar and STS 105107 (range 0 - 10 bar) with an accuracy of $10^{-3}$ bar. The temperature of the reaction chamber, gas manifold and fuel tanks was controlled to ensure that at all times the vapor partial pressure of each component remained below the saturation pressure for the given temperature.

Experiments have been performed using n-butyl formate $/ \mathrm{O}_{2} / \mathrm{Ar} / \mathrm{N}_{2}$ mixtures at peak pressures between 16 and 21 bar, and peak temperature between 680 and $861 \mathrm{~K}$ with typical compression times of up to $25 \mathrm{~ms}$. Butyl formate was obtained from Sigma Aldrich $(>97.0 \%$ purity), while all gases were supplied by Westfalen AG and Praxair, 99.996 \% argon, 99.95 \% nitrogen and $99.995 \%$ oxygen. 
Temperatures after compression have been determined indirectly using experimental pressure traces since direct measurement of the temperature in the RCM is not possible. It is assumed that the effect of heat loss to the wall during and after the compression stroke is limited to a thin boundary layer along the wall of the reaction chamber and the majority of the reaction chamber remains unaffected by heat loss. The unaffected region of the chamber away from the wall can be assumed to be compressed adiabatically. From the experimental pressure trace and initial experimental conditions, e.g. initial temperature and initial pressure, the compressed gas temperature, $T_{\mathrm{c}}$, at top dead center (TDC) is given by the following relation

$$
\int_{T_{0}}^{T_{c}} \frac{\gamma}{\gamma-1} \frac{d T}{T}=\ln \left[\frac{P_{c}}{P_{0}}\right]
$$

where $T_{\mathrm{c}}$ and $P_{\mathrm{c}}$ are temperature and pressure at TDC, $T_{0}$ and $P_{0}$ are initial temperature and pressure before compression begins, and $\gamma$ is the ratio of specific heat at constant pressure to specific heat at constant volume.

\subsection{Combustion vessel}

Experiments for determining laminar burning velocities were performed using a high-pressure chamber combined with an optical Schlieren cinematography setup at elevated pressures and temperatures. The experimental setup is shown schematically in Fig. 2 and has been described in detail by Hyvönen [14]. The internal shape of the pressure vessel is spherical with an inner diameter of $100 \mathrm{~mm}$; the quartz windows with a diameter of $50 \mathrm{~mm}$ are positioned on opposite sides. A Schlieren imaging system combined with a high-speed CCD camera is employed to observe the expanding flame, examples of such images of expanding flames have been given in Table 2 .

An external mixing vessel, directly connected to the combustion chamber, is used for a separate preparation of the air/fuel mixture. A homogeneous mixture is generated in the chamber before spark ignition. A two-step ignition system is used to ignite the mixture at the midpoint of the vessel with extended spark plug electrodes of $1 \mathrm{~mm}$ diameter.

All experiments were performed with compressed air, which consists of $20.94 \%$ oxygen, $78.13 \%$ nitrogen and $0.93 \%$ argon. The initial temperature of the fuel-air mixture inside the 
combustion vessel prior to ignition was $373 \mathrm{~K}$ and the initial mixture pressure $10 \mathrm{bar}$.

Experiments were conducted with equivalence ratios between 0.8 and 1.2.

A non-linear model has been utilized in this study for extracting the laminar flame speed, which has been discussed by Halter et al. [15] as well as by Kelley et al. [16]

$$
\ln \left(S_{b}\right)=\ln \left(S_{b}^{0}\right)-S_{b}^{0} L_{b} \frac{\kappa}{S_{b}^{2}},
$$

where $\mathrm{S}_{b}$ is the propagation speed with respect to the burnt mixture, and $\mathrm{L}_{b}$ is the Markstein length. $S_{b}{ }^{0}$ is the unstretched laminar flame speed of the burnt mixture and $\kappa=\left(2 / \mathrm{r}_{f}\right) \mathrm{S}_{b}$ is the stretch rate for a propagating spherical flame. The propagation speed $\mathrm{S}_{b}$ is determined by

$$
S_{b}=\frac{d r_{f}}{d t}
$$

where $r_{f}$ is the flame radius and $t$ is the time. Experimental measurements were restricted to spherical smooth flame fronts with diameters above $5 \mathrm{~mm}$ in order to avoid spark influences as a result of the ignition process [17]. The flame front was extracted from the captured Schlieren images by the method of Otsu et al. [18]. The image post-processing of the propagating flame was performed under the assumption of constant pressure and only data was used obtained before a noticeable rise of pressure.

The laminar burning velocity $S_{L}$ is defined as the unstretched flame displacement speed with respect to the unburnt mixture, $S_{u}{ }^{0}$. It is determined by mass continuity through a planar unstretched flame [19],

$$
S_{L}=S_{u}^{0}=S_{b}^{0}\left(\frac{\rho_{b}}{\rho_{u}}\right),
$$

Here, $\rho_{\mathrm{b}}$ and $\rho_{\mathrm{u}}$ are the densities of the burnt and unburnt mixture, where $\rho_{\mathrm{b}}$ is evaluated at adiabatic flame temperature conditions.

\section{Detailed kinetic model development}

Several studies on the oxidation of small alkyl esters, such as methyl formate and ethyl formate, have appeared over the last few years [6-8]. However, no prior model existed for nbutyl formate to the authors' knowledge. During the development of a kinetic model for the combustion of n-butyl formate our starting point has been a full $\mathrm{C}_{0}-\mathrm{C}_{4}$ base chemistry set, 
which will be described in more detail below. To this large base mechanism the submechanisms for the consumption of the fuel and the produced combustion intermediates have been added as described below. Both the high and low temperature chemistry are described to simulate, analyse and explain the experimentally observed laminar burning velocity and ignition delay trends including negative-temperature coefficient (NTC) behaviour. The complete mechanism, consisting of 301 species and 2501 reactions, is provided as supporting material including a species list providing the molecular structures.

The automatic chemical reaction mechanism generator RMG has been used, with the base chemistry subsets as seed mechanism, to generate a first overview of possible reaction paths [20]. Next, most RMG estimates for the rate coefficient expressions of the fuel oxidation pathways have been further improved through analogy with the according reactions of ethyl formate, methyl formate and n-butanol [6;7;21]. Based on the well studied combustion of these three oxygenated fuels, more possible reaction paths are included.

The modelling computations in this study have been conducted in CHEMKIN PRO [22] using the closed homogeneous reactor and the premixed laminar flame-speed calculation for the ignition delay times and flame speed simulations, respectively. The model has been developed and tested with the latest version, 15101, of CHEMKIN PRO. The 0-D closed homogenous reactor can be applied for the RCM and shock tube simulations as the effects of pressuregradients on the shock tube and compression and heat loss in the RCM can be captured using a volume profile.

\section{1 $\mathrm{C}_{0}-\mathrm{C}_{4}$ Base Chemistry}

The base chemistry set is assembled following a hierarchical approach and can thus be divided into several subsets. The $\mathrm{H}_{2} / \mathrm{O}_{2}$ submechanism is adopted from the recent work of Burke et al. [23]. The CO chemistry is from the Haas et al. syngas work [24]. Further $\mathrm{C}_{1}$ chemistry, including the important intermediate formaldehyde, and the $\mathrm{C}_{2}$ chemistry are adopted from the ethanol combustion model from Lee et al. [12]. Next, a subset containing the methyl formate reactions from Dooley et al. is included $[7 ; 8]$ as this is a possible intermediate and is not present in the ethanol model. The decompositions of n-butyl formate and its primary reactions lead partly to the formation of the n-butyl radical. Therefore the complete n-butane model, except for the $\mathrm{C}_{0}-\mathrm{C}_{2}$ chemistry already discussed, of Healy et al. 
[25] is included. This mechanism contains subsets for several important butyl formate oxidation intermediates such as n-butanal and n-propanal. All these subsets are finally incorporated into the chemical mechanism from Blanquart et al. [26;27] for the combustion of hydrocarbons and substituted aromatic species including soot precursor formation. All reactions involving species containing more than four carbon atoms are listed as a separate subset, which the user can include in order to capture the formation of aromatics or exclude to reduce the simulation computation time for general parameters such as the ignition delay times and the laminar burning velocities.

\subsection{Butyl formate chemistry}

\subsection{1 n-Butyl Formate Bond dissociation energies}

Bond dissociation energies (BDEs) of the global minimum energy configuration of butyl formate from each of the five $\mathrm{C}$ atoms calculated at CBS-QB3 level of theory are reported in Fig. 3 in the units of $\mathrm{kcal} / \mathrm{mol}$. The $\mathrm{C}_{\alpha}-\mathrm{H}$ and $\mathrm{C}_{\gamma}-\mathrm{H}$ bonds have very close BDEs of 97.1 and $97.7 \mathrm{kcal} / \mathrm{mol}$ respectively, in reasonable agreement with the $\mathrm{C}_{\alpha}-\mathrm{H}$ BDE value calculated at the same level of theory for other ester molecules [28;29]. The $\mathrm{C}_{\beta}-\mathrm{H}$ bond has a slightly higher value of $98.9 \mathrm{kcal} / \mathrm{mol}$, comparable to the formate hydrogen BDE (98.2). The $\mathrm{C}_{\delta}-\mathrm{H}$ bond has the notably higher BDE, which is expected for a primary site in the alkyl chain, of $100.7 \mathrm{kcal} / \mathrm{mol}$ and is the strongest $\mathrm{H}$-bond of n-butyl formate. The comparison with methyl butanoate in table 3 shows that the $\alpha, \beta$ and $\gamma$ site in $n$-butyl formate have BDE's similar to the $\beta$ site in methyl butanoate while the $\delta$ site in $n$-butyl formate resembles the $g$ site in methyl butanoate. In the lowest energy conformation of $n$-butyl formate, the $\gamma$ and $\beta$ hydrogens have similar distance from the oppositely charged ether oxygen. This could be the reason why the $\gamma$ BDE is still in the range of the $\alpha$ and $\beta$ BDE's. These findings reveal that the $\alpha, \beta$ and $\gamma$ hydrogen atoms could be energetically favourable abstraction sites over the $\delta$ hydrogen by $\mathrm{H}$, $\mathrm{OH}$ and $\mathrm{HO}_{2}$ radicals for the oxidation process in combustion.

\subsubsection{Fuel decomposition}

Several decomposition pathways are possible for a small alkyl ester, like n-butyl formate. The unimolecular decomposition initiation reactions involving breaking a $\mathrm{C}-\mathrm{O}$ bond to produce $\mathrm{n}$ butyl or n-butoxy radicals have been included with the rate coefficients from the 
corresponding bond breakings in ethyl formate and methyl formate [6;7]. Further, butyl formate can also decompose via molecular elimination of $\mathrm{CO}_{2}$ or $\mathrm{CH}_{2} \mathrm{O}$ producing n-butane or n-butanal with rate constants again estimated based on ethyl formate reactions. A final possible decomposition pathway produces 1-butene and formic acid via a six-membered ring transition state similar to ethene elimination from ethyl formate [6].

\subsubsection{Hydrogen abstraction from fuel}

This class of reactions includes abstraction of $\mathrm{H}$ atoms from the fuel by small radical species and fuel radicals. The important rate coefficients of the abstractions by $\mathrm{HO}_{2}$ and $\mathrm{H}$ have been obtained from quantum chemical calculations at a high level of theory. A publication presenting these valuable computations is in preparation [30]. The rate coefficients have been calculated by transition state theory for each hydrogen atom and summed for the hydrogen atoms belonging to the same carbon atom. Barrier heights were computed for the lowest energy conformation and evaluated with the advanced double hybrid density functional B2KPLYP [31]. The $\mathrm{HO}_{2}$ radical can approach the hydrogen to be abstracted in more than one favourable orientation: the $\mathrm{OH}$ end of the radical can rotate around the bond axis or the $\mathrm{H}$ around the $\mathrm{O}-\mathrm{O}$ axis of the $\mathrm{HO}_{2}$. The rate constants we use capture these several possible transition states per hydrogen in a hindered rotor treatment rather than using the standard rigid-rotor harmonic oscillator model.

All other abstraction rate coefficients are estimated from a comparison with the abstractions from ethyl formate [6] for the alpha- and the formate-hydrogens and from a comparison with n-butanol [21] for the gamma- and delta-hydrogens. The beta abstraction rate constants are the ethyl formate beta rate constants scaled by 0.66 , as only two $\mathrm{H}$ atoms are available for abstraction instead of three, to an expression in between the values for the primary beta site in ethyl formate and the secondary beta site in n-butanol. The obtained rate coefficient expression for abstraction of a hydrogen atom by $\mathrm{H}, \mathrm{OH}$ and $\mathrm{HO}_{2}$ are given in Table 4 .

\subsubsection{Fuel radical decompositions}

The five possible radicals produced by hydrogen abstraction from the fuel can at higher temperatures all be consumed by decompositions. At lower temperatures, mainly oxygen addition dominates the consumption of these combustion radicals. Decomposition is primarily by beta-scission of one of the $\mathrm{C}-\mathrm{O}$ bonds or a $\mathrm{C}-\mathrm{C}$ bond for the gamma and delta radical as no beta $\mathrm{C}-\mathrm{O}$ bonds are present. The beta $\mathrm{C}-\mathrm{O}$ bond breaking rate constants have been estimated 
from analogy with the corresponding decompositions of ethyl formate primary radicals [6], while the beta-scissions of C-C bonds are based on the similar reactions of the n-butanal fuel radicals [25]. The most efficient beta scission pathways are the alpha radical's decomposition to yield butanal and $\mathrm{HCO}$ and the $\mathrm{C}_{4} \mathrm{H}_{9} \mathrm{OCO}$ (n-butoxy formyl) decompositions to either $\mathrm{CO}_{2}$ and n-butyl or CO and n-butoxy radical. Therefore, the peroxy chemistry on the alpha site and formyl site has a negligible influence compared to the other primary radicals' low temperature peroxy chemistry. The branching fractions between n-butyl and n-butoxy formation from nbutoxy formyl proves sensitive at lower temperatures as n-butyl is more reactive through peroxy reactions.

\subsubsection{Radical isomerisation}

The primary radicals produced upon abstraction of one of the H-atoms from butyl formate can isomerize by transferring $\mathrm{H}$-atoms from any carbon atom to the radical site. Only 5-member and 6-member transition rings have been considered as others are too slow to be of influence. This limits the possible isomerisation pathways to hydrogen transfers from alpha- to delta-, gamma- to formate- and delta- to formate-carbon atoms. The rate constants for these reactions are estimated by analogy with similar transitions [21].

\subsubsection{Low Temperature Oxidation pathways}

To accurately simulate and analyze the ignition data in the low temperature $(<1000 \mathrm{~K})$ regime, the present model includes the addition of molecular oxygen to the fuel radicals to form peroxy species and the subsequent reactions of these species leading to possible lowtemperature branching paths. Several studies have made an attempt at accurately describing the peroxy chemistry for the oxidation of alkanes and alcohols such as n-butane [25] and nbutanol [13;21], although for many elementary steps in the low-temperature oxidation pathways of these fuels only rough estimations for their rate coefficient expressions are available. For small alkyl esters, no validated low-temperature mechanism is available in the literature to the author's knowledge. A recent methyl formate mechanism includes additions of molecular oxygen to form $\mathrm{RO}_{2}$ (peroxy radicals), but has not been validated against lowtemperature data [7]. Therefore, the low-temperature chemistry has been adopted and modified from the n-butanol work of Sarathy et al. [21] for the radicals formed by Habstraction from one of the $\mathrm{C}$-atoms in the butyl chain of butyl formate. Further, all low- 
temperature chemistry for the n-butoxy formyl radical is based on the methyl formate oxidation [7].

Despite the differences in molecular structure between n-butanol and butyl formate, and the different products of their low-temperature reactivities, the n-butanol rate constants can be applied as a good approximation for the butyl formate rate constants since similar bonds are being formed or broken. Imposing the n-butanol $\mathrm{R}+\mathrm{O}_{2}$ to $\mathrm{RO}_{2}$ equilibrium for instance, can have a significant influence and further study on these crucial reactions for the n-butylformate mechanism will further improve the mechanism.

The low-temperature branching path is the sequence of the following elementary steps:

a. Addition of $\mathrm{O}_{2}$ to fuel radicals $\left(->\mathrm{RO}_{2}\right)$

b. Isomerization of the $\mathrm{RO}_{2}$ product to $\mathrm{QOOH}$

c. Addition of a second $\mathrm{O}_{2}$ to the $\mathrm{QOOH}$ product $\left(\mathrm{O}_{2} \mathrm{QOOH}\right)$

d. Elimination of $\mathrm{OH}$ from $\mathrm{O}_{2} \mathrm{QOOH}$ and formation of a carbonyl alkyl formate hydroperoxide species

e. Decomposition of carbonyl alkyl formate hydroperoxide species to $\mathrm{OH}$ and oxygenated products

The rate coefficients of molecular oxygen addition to the fuel radicals depends on the nature of the radical carbon, either primary or secondary, with rate constants as for n-butanol radicals [21] and rate constant expressions for the re-dissociation of the peroxy radicals formed are estimated to be equal to the according dissociation of the n-alkyl peroxy radicals [25]. The final products of the low temperature branching pathway are thus two $\mathrm{OH}$ radicals, a fuel radical specific oxygenated radical $\left(\mathrm{HCO}, \mathrm{CH}_{3} \mathrm{CO}\right.$, etc.), and a stable oxygenate (aldehyde, esters with an extra aldehyde/ketone functional group, etc.). The further consumption of these species through decomposition or hydrogen abstraction reactions is included based on the analogy with the consumption of similar species in the oxidation of ethyl formate and methyl formate [6;7]. For a few species no analogous reaction exists and the rate coefficients are estimations based on RMG additivity rules [20].

Other reactions and decompositions of $\mathrm{RO}_{2}$ and $\mathrm{QOOH}$ compete with the chain branching paths and lead to formation of several combustion intermediates $\left(\mathrm{RO}_{2} \mathrm{H}, \mathrm{RO}\right.$, unsaturated esters, and cyclic ethers). These chain propagating pathways, including the consumption of the intermediates, have all been included based on the analogy from the n-butanol lowtemperature mechanism as well [21]. One important class of reactions, as identified through 
sensitivity analysis given below, is the elimination of $\mathrm{RO}_{2}$ to $\mathrm{HO}_{2}$ and an olefin. These rate coefficients are thus identical to the according rate coefficients of the butanol low-temperature chemistry. A few modifications are made within the uncertainty limits for these reactions to bring the model simulations into better agreement with the available validation data. The rate constant of the hydrogen abstraction from QOOH species (butylhydroperoxy formate radical) by molecular oxygen is decreased to better describe the low-temperature trend in the ignition delay times of butyl formate combustion. Additionally, the rate constant of the $\mathrm{HO}_{2}$ elimination from the $\mathrm{QOOH}$ species is altered to the slower rate constant expression of other QOOH elimination pathways [21]. These changes seem fair given the large uncertainties of these rate coefficients. Further, we have described the addition of the fuel radicals to $\mathrm{O}_{2}$ using a forward and reverse rate constant based on the n-butanol reactions, since the uncertainty on the thermo data estimations of the fuel radicals might significantly influence the model performance otherwise. Currently, this first combustion mechanism for n-butyl formate is not yet completely internally consistent due to these adaptions. Several rate constants have been estimated based on methyl formate rates and are therefore not fully consistent with the n-butyl formate thermochemistry. Further study of this interesting molecule will focus on these topics.

The alpha- $\mathrm{RO}_{2}$ peroxy-radical can undergo a six-membered ring isomerisation to abstract the hydrogen atom from the formate site. This isomerisation is followed by a rapid decomposition to yield n-butanal, $\mathrm{CO}_{2}$ and $\mathrm{OH}$. This type of pathway is similar to Waddington chemistry for alkene and alcohol oxidations where a beta- $\mathrm{RO}_{2}$ abstracts, via a six-membered ring transition, the hydroxy-hydrogen and subsequently decomposes [21]. The rate constant expression is thus based on analogy with six-membered Waddington transitions. This chain propagating pathway can add to the alpha-peroxy radical consumption for formate esters and competes with the QOOH branching pathways. The Waddington type reactions of the n-butanol peroxy chemistry do not have analogous reactions for n-butyl formate peroxy chemistry due to the differences in molecular structure.

The current model also allows low temperature chemistry for the radical with the formate $\mathrm{H}$ atom abstracted, n-butoxy formyl, starting from addition of oxygen to this site. This part of the low-temperature chemistry is adopted from the methyl formate mechanism of Dooley et al. [7], which is based on the work of Fischer et al. [32]. However, this methyl formate oxidation mechanism had not been validated against low-temperature data. The addition of oxygen to the formate radical site can be followed by internal hydrogen transition to a QOOH species and a second oxygen addition. This product dissociates in two steps to give two $\mathrm{OH}$ 
radicals and is thus a branching path. Chain propagating pathways for the intermediates have been captured in the mechanism as well.

The influence of both alpha-peroxy-radical chemistry and n-butoxy formyl is relatively small compared to the peroxy radicals of other sites in the n-butyl chain of butyl formate, since the alpha-radical and n-butoxy formyl efficiently decompose via beta-scissions of a C-O bond.

\subsection{Thermochemistry}

Enthalpies of formation have been calculated for n-butyl formate, its primary radicals and several combustion intermediates with the CBS-QB3 method from comparison with atomization energies [33]. The CBS-QB3 method has been tested against the 148 heats of formation in the G2/97 test set with a mean absolute deviation amounting to $1.1 \mathrm{kcal} / \mathrm{mol}$ (largest error of $6.6 \mathrm{kcal} / \mathrm{mol}$ ) [34]. For our calculations, the most stable n-butyl formate conformation has been used, having the lowest evaluated energy with both the hybrid B3LYP functional and the double hybrid B2K-PLYP functional. From this lowest-energy conformation, the radicals and further species can be derived by elimination of the respective atoms and geometry reoptimization. Saeys et al. have investigated different reaction schemes to obtain accurate standard enthalpies of formation from the CBS-QB3 method. In contrast to purely quantum mechanical methods, for this compound method the best prediction of standard enthalpies of formation was achieved with reference to atomization energies [33]. This is the way in which theoretical molecular heats of formation have been obtained during the CBS-QB3 model development [34]. Therefore, we use the same reference reaction $\left(\mathrm{C}_{k} \mathrm{H}_{l} \mathrm{O}_{m} \rightarrow k \mathrm{C}+l \mathrm{H}+m \mathrm{O}\right)$ for our calculation of standard enthalpies of formation. Since in the calculation of bond dissociation energies the contribution of the elements cancels out, the balance reduces to the difference of the enthalpies of the dissociation products to the enthalpy of n-butyl formate and we again refer to atomization energies when we use CBS-QB3 for the same reasoning as above.

Thermodynamic contributions to the CBS-QB3 enthalpies are obtained with the Rigid Rotor Harmonic Oscillator (RRHO) model in Gaussian [35]. A known shortcoming of the RRHO model is the exclusion of internal rotations that can affect the thermodynamic contributions to enthalpy, heat capacity and entropy significantly. The possible influence of internal rotations is checked by performing torsional scans with the B3LYP density functional and tzvp (triple 
zeta valence polarisable) basis set and using the TAMkin python package [36]. This is applied to obtain hindered rotation energy levels from which partition functions to calculate enthalpy, heat capacity and entropy are derived. Heat capacity values do not differ significantly between both models. The enthalpy values are $0.71 \mathrm{kcal} / \mathrm{mol}$ lower than predicted with RRHO at $1500 \mathrm{~K}$ with increasing differences at higher temperatures. The entropy with hindered rotation included is consistently 4.8 to $7.2 \mathrm{cal} / \mathrm{mol} \mathrm{K}$ larger over the whole temperature range. However, knowing these uncertainties, calculating equilibrium constants and reverse reaction rate constants requires entropy and enthalpy differences between reactants and products rather than absolute entropy values. Therefore, we consequently used the RRHO treatment in the CBS-QB3 method.

The standard two sets of seven NASA polynomial coefficients, one for the low temperatures up to $1000 \mathrm{~K}$ and one for the higher temperatures, have been fitted to the calculated thermochemical data and are given in the supporting information. The low temperature set was forced to meet exactly the highly accurate standard enthalpy of formation at $298.15 \mathrm{~K}$. The high temperature set was forced to equal the low temperature set at $1000 \mathrm{~K}$ for the enthalpy, heat capacity and entropy. The maximum deviation of the polynomials from the CBS-QB3 calculated values from $200 \mathrm{~K}$ to $4000 \mathrm{~K}$ amounts to only $0.15 \mathrm{kcal} / \mathrm{mol}$ in the enthalpy and $0.3 \mathrm{cal} / \mathrm{mol} \mathrm{K}$ in the entropy. The calculated thermodynamic data for n-butyl formate and its primary radicals are listed in Table 5.

For all species in the $\mathrm{C}_{0}-\mathrm{C}_{4}$ base chemistry, the thermodata are from the same sources as the kinetic rate coefficient data. The thermochemical data of the remaining species, mainly lowtemperature combustion intermediates, have been calculated using the thermo-data estimator tool of RMG [20] based on additivity rules. These rougher estimations are sufficient as the reverse reactions in which these intermediates are involved, are less influential.

\subsection{Transport properties}

The transport parameters of all the species in the kinetic model are required to simulate the laminar burning velocity data. For all species in the $\mathrm{C}_{0}-\mathrm{C}_{4}$ base chemistry subset, the transport properties are used from the models for these smaller species [7;12;23-25]. Transport parameters for the butyl formate mechanism's species are calculated using the transport data estimator of RMG based on group additivity rules [20], used in particular for the LennardJones sigma and epsilon parameters. 


\section{Results and discussion}

\subsection{High pressure shock tube ignition delay times}

Table 6 lists all experimental ignition delay time measurements from the HPST facilty for nbutyl formate at 20 bar and 90 bar. For both pressures, stoichiometric fuel/air mixtures have been used and the results are plotted in Fig. 4, showing temperature dependence characteristics similar to normal alkanes. At temperatures greater than $1050 \mathrm{~K}$, Arrhenius temperature dependence is observed for the ignition delays. Below $1000 \mathrm{~K}$, the measured ignition delay times deviate from the Arrhenius temperature dependence as the dependence on temperature diminishes with the onset of mild negative-temperature-coefficient (NTC) behavior. At temperatures below $750 \mathrm{~K}$ at 20 bar, the ignition delay times start to increase again Arrhenius-wise with decreasing temperatures, showing linearity on a semi-log plot against $1000 / T$. At 90 bar, the NTC influence is limited to the temperature regime of $1000 \mathrm{~K}$ down to $850 \mathrm{~K}$. At even lower temperatures, transition to Arrhenius temperature dependence is determined. The pressure dependence of the auto-ignition delay times is strongest in the NTC regime, with changes in ignition delays upon increasing the pressure from 20 to 90 bar by a factor of 8 . The reactivity increases with increasing pressure as has been observed for other fuels.

\subsection{Rapid compression machine ignition delay times}

To further extend the temperature range for the auto-ignition delay times from intermediate to low temperatures, experiments have been performed in the RCM at pressures of about 20 bar over the temperature range of $860 \mathrm{~K}$ down to $645 \mathrm{~K}$. Experiments over a range of compressed temperatures are obtained for nearly constant compressed pressures through variations in initial temperature, pressure, diluents composition and compression ratio. The composition of the inert diluent does not seem to have an effect on measured ignition delays. A complete overview of the RCM experimental results for n-butyl formate in stoichiometric air is given in Table 7. Fig. 5 illustrates the definition of the ignition delay time, defined as the time difference between the end of compression and the highest peak in the pressure derivative at ignition. After the end of the compression, the pressure slightly drops due to the influence of heat loss until the chemical reactions drive the combustion mixture to ignition and the pressure sharply increases. For all experiments in the temperature range of 710 up to $760 \mathrm{~K}$, a 
first increase in pressure prior to the ignition is observed. An example of such a cool flame event is depicted in the pressure trace plotted in Fig. 5. It appears $7.2 \mathrm{~ms}$ after the end of compression (4.0 ms prior to total ignition) as a pressure increase of $1.5 \mathrm{bar}$. All first stage ignition delay times are plotted as a function of temperature in Fig. 6. As temperature increases, the cool flame event occurs earlier, the time difference with the main ignition event lengthens and the associated pressure rise diminishes until the pressure rise becomes too weak to be able to determine a cool flame. At lower temperatures, the difference in time between the cool flame and main ignition shortens until no separate cool flame related pressure rise can be observed. These findings are similar to cool flame behavior observed for n-butane ignition by Healy et al. [25].

Fig. 4 shows a comparison of the ignition delay data obtained from HPST and current RCM data, proving the complementary nature of both experimental set-ups. It is important to note that the experimental results both with shock tube and RCM are in excellent agreement, in the overlapping regime for both facilities. The measured ignition delay times determined at about 20 bar in both facilities can be directly compared at $850 \mathrm{~K}$ proving the consistency of both data sets. The shock tube results show the high temperature ignition regime and transition to the intermediate temperature regime below $900 \mathrm{~K}$. The RCM measurements yield data in this mild NTC temperature regime from about $900 \mathrm{~K}$ to $750 \mathrm{~K}$ at 20 bar. The ignition delay times remain nearly constant as function of temperature in the NTC regime and only start to increase significantly as temperatures drop below $750 \mathrm{~K}$. After transition into the low temperature regime, normal Arrhenius behavior is again observed for the ignition delay time data. In the mild NTC regime, the ignition delay times depend strongly on the compressed pressure. The observed feature at about 1.4-1.35 1000/T thus indicates the experimental scatter, which is caused by changes in compressed pressure combined with the repeatability and reproducibility of the device.

\subsection{Ignition delay time simulations and analysis}

The performance of the new detailed kinetic model against all shock tube and RCM ignition data is presented in Fig. 4. All model predictions have been simulated using CHEMKIN-PRO [22]. The onset of ignition has been determined in the simulations as the point of maximum temperature rise, which corresponds closely to the point of maximum pressure rise. As a first assumption, constant-volume adiabatic calculations were performed with $\mathrm{N}_{2}$ as the sole bath gas for reflected shock or end of compression conditions of 20 bar and 90 bar and the 
complete temperature range (plotted as con. vol. in Fig. 4). This yields reasonably accurate results, but a more detailed comparison requires simulations considering the full pressure profile of the RCM in the calculations, with compression and heat loss, as chemical species formed during compression can affect the autoignition process [37]. Therefore, a volume profile is specified for all RCM model simulations to exactly match the experimental pressure profile from the start until the end of the compression and further during the delay until ignition when heat-loss is observable. This is done for the gas mixtures used, based on nonreactive pressure profiles measured for each reactive experimental RCM condition [37]. The inclusion of a volume profile decreases the shorter ignition time predictions due to the compression and increases the longer ones due to the heat loss influence.

In all shock tube experiments, a positive pressure gradient is observed for the post reflected shock conditions due to shock attenuation. On average this pressure gradient, $\mathrm{d} / \mathrm{dt}\left(\mathrm{p} / \mathrm{p}_{0}\right)$, amounts to only $2.5 \% / \mathrm{ms}$ at 90 bar and $4.5 \% / \mathrm{ms}$ at 20 bar. This influence is simulated by including a volume profile to match these pressure gradients.

Figure 4 depicts the predictions using the detailed approaches explained. A simulated RCM pressure profile is compared to the experimentally observed pressure trace in Fig. 5, showing the accurate match between both, prior to the cool flame event.

Close agreement between the model simulations and all ignition data is observed proving the good performance of the presented mechanism. The model accurately shows the observed trends at 20 bar and 90 bar of a mild NTC intermediate temperature regime combined with Arrhenius behaviour for both the low and high temperature regimes. The effect of pressure on the ignition delay times with strong pressure dependence in the NTC regime is well simulated. Only slight overpredictions of the ignition times at the highest and the lowest temperatures for the experiments at about 20 bar, combined with a more pronounced NTC for the simulations at this pressure leading to underpredicting the ignition delays around $800 \mathrm{~K}$ are the small differences of model predictions and experimental data.

The model accurately predicts the occurrence of experimentally observed cool flame events in the NTC regime, as shown in the simulation depicted in Fig. 5. The mechanism also predicts the experimentally observed trends of stronger first-stage pressure rises with shorter time lags between the first and second ignition stages for lower temperatures, shown in Fig. 6. As the temperature increases, the cool flame pressure rise reduces until it is no longer observable in the simulations above $850 \mathrm{~K}$. At temperatures less than $700 \mathrm{~K}$, the difference between the first and second stage becomes too small to identify two separate stages. The model thus 
accurately captures the cool flame reactivity; although it overestimates the first stage pressure rise and consistently predicts longer first stage ignition time delays.

Further insight in n-butyl formate reactivity is gained by performing a reaction path analysis at $20 \%$ fuel consumption for a stoichiometric mixture at $750 \mathrm{~K}$ and 20 bar, an RCM experimental condition in the NTC regime with clear two-stage ignition. The important reaction paths are schematically given in Fig. 7. The first step in the oxidation of the fuel at this temperature is mainly the abstraction of one of the $\mathrm{H}$ atoms from n-butyl formate by $\mathrm{OH}$, leading to five possible primary radicals. The radicals show significant differences in consecutive chemistry. Upon abstraction of the hydrogen from the formate group, the $\mathrm{C}_{4} \mathrm{H}_{9} \mathrm{OCO}$ decomposes to n-butyl and $\mathrm{CO}_{2}$ or butoxy radical and $\mathrm{CO}$. n-Butyl formation enhances the reactivity more as it adds molecular oxygen leading to subsequent peroxy chemistry while a further decomposition of n-butoxy to propyl is required to enable peroxy chemistry from this radical. The efficient beta scission of alpha radicals $\left(\mathrm{A}-\mathrm{C}_{4} \mathrm{H}_{8} \mathrm{OCHO}\right)$ leads to the formation of the relatively stable intermediate n-butanal and hinders the low temperature reactivity from this radical site. Beta radicals $\left(\mathrm{B}-\mathrm{C}_{4} \mathrm{H}_{8} \mathrm{OCHO}\right)$ mainly add to oxygen molecules, since beta scission of these radicals has much less influence at $750 \mathrm{~K}$. The further low temperature reactions of the peroxy radical are isomerisation to yield a hydroperoxy radical $(\bullet \mathrm{QOOH})$, elimination of $\mathrm{HO}_{2}$ to yield a relatively stable unsaturated ester or re-dissociation. If a second oxygen molecule adds to a hydroperoxy radical the produced intermediate $(\bullet \mathrm{OOQOOH})$ decomposes in two steps yielding two hydroxyl radicals. This sequence of reactions is the main low temperature branching path. The gamma (C$\left.\mathrm{C}_{4} \mathrm{H}_{8} \mathrm{OCHO}\right)$ and delta $\left(\mathrm{D}-\mathrm{C}_{4} \mathrm{H}_{8} \mathrm{OCHO}\right)$ radicals show similar reactivity to the beta radical since they do not have $\mathrm{C}-\mathrm{O}$ bonds in beta position and therefore mainly react via oxygen addition.

Since the primary radicals show quite different reactivity, the branching between their production channels is crucial for n-butyl formate oxidation. To further analyze the detailed mechanism, sensitivity analyses for both the cool flame and the main ignition stage have been conducted for the same conditions as the reaction path analysis, $750 \mathrm{~K}$ and 20 bar. A summary of the most influential reactions under these conditions is given in Fig. 8. The sensitivity is here defined as the difference in ignition delay time or cool flame delay time upon dividing the A-factor of the respective reaction by two and multiplying it by two and further dividing this difference by the original delay time. A positive sensitivity thus 
characterizes reactions which enhance the reactivity of the fuel while reactions with a negative sensitivity inhibit the fuel's reactivity.

sensitivity $=\left(t_{i g n, k / 2}-t_{i g n, k^{*} 2}\right) / t_{i g n}$

The sensitivity plot for $750 \mathrm{~K}$ confirms the reaction path analysis with dominant chemistry in the NTC temperature regime being the abstraction of hydrogen atoms from n-butyl formate and the subsequent peroxy chemistry of the radicals formed. The chemistry is almost exclusively driven by $\mathrm{OH}$ radicals. During the first ignition stage, only the peroxy reactions leading to $\mathrm{OH}$ production via the low-temperature branching pathways discussed earlier appear as sensitive. The crucial chain terminating reactions are the production of the unstable alpha radical, which leads to the stable intermediate n-butanal, $\mathrm{HO}_{2}$ elimination from peroxy species and $\mathrm{C}_{4} \mathrm{H}_{9} \mathrm{OCO}$ dissociation to yield n-butoxy with some contribution from $\mathrm{HO}_{2}$ self reaction. For the main ignition, the $\mathrm{H}_{2} \mathrm{O}_{2}$ decomposition starts to add to chain branching while this pathway is insensitive during the cool flame event.

At higher temperatures, the fuel specific peroxy radical chemistry becomes less influential as illustrated by the sensitivity plot for $1050 \mathrm{~K}$ and 20 bar in Fig. 9. At this temperature, most of the sensitive reactions involve production or consumption of $\mathrm{HO}_{2}$ and $\mathrm{H}_{2} \mathrm{O}_{2}$, which on decomposition yields two hydroxyl radicals and this is the main branching path in this temperature regime and thus the most influential reaction. Recombination of $\mathrm{HO}_{2}$ is the main chain terminating reaction. The chemistry of smaller species containing only one or two carbon atoms gains importance as the rate coefficients of radical scission reactions quickly increase at higher temperatures. At further increased temperatures, the reaction of hydrogen atoms with oxygen molecules to produce hydroxyl radicals and oxygen atoms starts to dominate over $\mathrm{H}_{2} \mathrm{O}_{2}$ chemistry and becomes the dominant branching path.

\subsection{Laminar burning velocities}

In this section, experimental data for laminar burning velocities are presented, and the proposed kinetic model is validated against these data. The combustion of n-butyl formate in a premixed flame environment was investigated in these experiments. Figure 10 shows experimentally and numerically obtained laminar burning velocities at equivalence ratios from 0.8 to 1.2 for initial temperatures and pressures of $373 \mathrm{~K}$ and 10 bar. Calculations are 
performed using the CHEMKIN-PRO premixed laminar flame speed calculator [22]. Simulations included thermal diffusive effects and multicomponent transport, and obtained solutions for large grids of up to 500 points and strict maximum gradient and curvature criteria between successive grid points (CURV and GRAD) of 0.05 .

For mixtures at an equivalence ratio of 0.8 to 1.1 , the burning velocity $\left(S_{L}\right)$ is successively increasing from a value of $19.51 \mathrm{~cm} / \mathrm{s}$ to a maximum burning velocity of $29.92 \mathrm{~cm} / \mathrm{s}$. After it has reached a maximum, it slowly decreases to a value of $29.11 \mathrm{~cm} / \mathrm{s}$ at $\phi=1.2$. It can be observed that a maximum predicted burning velocity exists at an equivalence ratio of 1.1 with a value of $29.50 \mathrm{~cm} / \mathrm{s}$, which is $0.42 \mathrm{~cm} / \mathrm{s}$ lower than the experimental observation. The kinetic model slightly over-predicts the burning velocity values on the lean side and underpredicts at rich mixtures. Overall, it can be concluded that the predictions calculated using the present kinetic model agree well with the experimental measurements. The observed trends for the laminar burning velocities as a function of the equivalence ratio with a peak on the fuel-rich side is the general trend observed for the measured burning rates of hydrocarbons and the few oxygenates studied.

A sensitivity analysis for burning velocities was performed using the FlameMaster software package [38]. The sensitivity coefficients of the burning velocity are defined as

$$
S_{S_{L}}^{\alpha}=\frac{k_{\alpha}}{S_{L}} \frac{\partial S_{L}}{\partial k_{\alpha}} \quad \alpha=1, \ldots, M
$$

Here, $\mathrm{k}_{\alpha}$ is the rate constant of each reaction $\alpha$. Three equivalence ratios $(0.8,1.0$ and 1.2), which represent lean, stoichiometric and rich mixtures respectively, were chosen to investigate the sensitivities towards each reaction. Figure 11 shows results of the sensitivity analysis based on the present mechanism at a pressure of 10 bar and a temperature of $373 \mathrm{~K}$.

The prediction of burning velocities depends strongly on the reactions involving the small hydrocarbon species. The dominant high-temperature branching reaction between $\mathrm{H}$ and $\mathrm{O}_{2}$ to yield $\mathrm{O}$ and $\mathrm{OH}$ is the most influential reaction at all equivalence ratios. The competing reaction to form $\mathrm{HO}_{2}$ proves to be one of the main inhibiting reactions. Other crucial reactions include the consumption of methyl and $\mathrm{CO}$, and other $\mathrm{OH}, \mathrm{H}$ and $\mathrm{HO}_{2}$ reactions. An accurate $\mathrm{H}_{2} / \mathrm{CO} / \mathrm{CH}_{4}$ base mechanism is thus crucial for the prediction of the burning velocity. In Fig. 11, only fuel specific reactions have been included however; as the small species chemistry is relatively well know and the main interest of this study are the reactions specific 
to the combustion of n-butyl formate. This shows the main fuel specific reactions having an influence on the laminar burning velocities are the fuel radical decompositions.

\section{Summary and Conclusions}

The combustion of the biofuel candidate n-butyl formate has been studied at engine relevant conditions using three different experimental approaches. The intermediate to lowtemperature combustion behaviour is characterized by measuring the ignition delay times in the complementary experimental facilities of the high-pressure shock tube and rapid compression machine. Autoignition delay times have been recorded over the temperature range 645 to $1185 \mathrm{~K}$ for stoichiometric mixtures at pressures of about 20 and 90 bar. The RCM and shock tube data agree well each other within an overlap region at temperatures of about $850 \mathrm{~K}$ for the 20 bar data. Mild negative temperature coefficient behaviour is observed with nearly constant ignition delay times from 850 to $750 \mathrm{~K}$ at 20 bar. At the increased pressure of 90 bar, the NTC regime shifts to higher temperatures. The ignition delay times prove to be most sensitive to pressure in the NTC regime. In addition, the laminar burning velocities of n-butyl formate/air mixtures have been measured as a function of equivalence ratio. A peak burning velocity is observed on the fuel rich side at a value of about $\phi=1.1$, as is typical for other fuel compounds.

A detailed kinetic model, which describes the combustion of n-butyl formate has been constructed and is successfully validated against the presented experimental ignition delay times and laminar burning velocities. The accurate results of theoretical calculations for thermochemical data of the fuel and its important combustion intermediates have been included in the mechanism. Sensitivity and reaction path analyses show the importance of the peroxy chemistry for the chemistry leading to ignition at low temperatures. Two-stage ignition is observed in the experimental pressure traces for ignition experiments in the temperature range of 710 to $760 \mathrm{~K}$ and reproduced by the model simulations. At intermediate temperatures, initiation through hydrogen abstractions by $\mathrm{HO}_{2}$ from n-butyl formate are the dominant fuel-specific sensitive reactions. Theoretical studies of the hydrogen abstraction reactions from the fuel by $\mathrm{H}$ and $\mathrm{HO}_{2}$ have been performed and the results for these important reactions are incorporated into the detailed mechanism. The laminar burning velocities are mainly sensitive to the reactions of small intermediates, especially reactions of hydrogen atoms and hydroxyl radicals. 
This research paper presents an elaborate study of a novel biofuel candidate. Further, the experimental data and the presented mechanism capturing both the high and low temperature oxidation pathways of n-butyl formate add to the overall knowledge on the combustion of alkyl esters, an interesting class of biofuel compounds.

\section{Acknowledgements}

The authors thank the Cluster of Excellence "Tailor-Made Fuels from Biomass", which is funded by the Excellence Initiative by the German federal and state governments to promote science and research at German universities. The authors acknowledge Prof. William H. Green and Katherine Catani for helpful comments on this project. S. Vranckx acknowledges the support from the Alexander von Humboldt Foundation through the postdoctoral fellowship received.

\section{References}

[1] G.W. Huber, S. Iborra, A. Corma, Chem. Rev. 106 (2006) 4044-4098.

[2] C.K. Law, AIAA J. 50 (2012) 19-36.

[3] A.J. Janssen, F.W. Kremer, J.H. Baron, M. Muether, S. Pischinger, J. Klankermayer, Energy Fuels 25 (2011) 4734-4744.

[4] G. Knothe, Prog. Energy Combust. Sci. 36 (2010) 364-373.

[5] C.K. Westbrook, C.V. Naik, O. Herbinet, W.J. Pitz, M. Mehl, S.M. Sarathy, H.J. Curran, Combust. Flame 158 (2011) 742-755.

[6] C.K. Westbrook, W.J. Pitz, P.R. Westmoreland, F.L. Dryer, M. Chaos, P. Osswald, K. Kohse-Hoinghaus, T.A. Cool, J. Wang, B. Yang, N. Hansen, T. Kasper, Proc. Combust. Inst. 32 (2009) 221-228.

[7] S. Dooley, M.P. Burke, M. Chaos, Y. Stein, F.L. Dryer, V.P. Zhukov, O. Finch, J.M. Simmie, H.J. Curran, Int. J. Chem. Kinet. 42 (2010) 527-549.

[8] S. Dooley, F.L. Dryer, B. Yang, J. Wang, T.A. Cool, T. Kasper, N. Hansen, Combust. Flame 158 (2011) 732-741.

[9] M.H. Ghatee, F. Moosavi, A.R. Zolghadr, J. Mol. Liq. 167 (2012) 5-13.

[10] S. LeCalve, G. LeBras, A. Mellouki, J. Phys. Chem. A 101 (1997) 5489-5493. 
[11] K. Heufer, H. Olivier, Shock Waves 20 (2010) 307-316.

[12] C. Lee, S. Vranckx, K.A. Heufer, S.V. Khomik, Y. Uygun, H. Olivier, R.X. Fernandes, Z. Phys. Chem. 226 (2012) 1-28.

[13] S. Vranckx, K.A. Heufer, C. Lee, H. Olivier, L. Schill, W.A. Kopp, K. Leonhard, C.A. Taatjes, R.X. Fernandes, Combust. Flame 158 (2011) 1444-1455.

[14] J.J.Hyvönen, Ph.D Thesis, RWTH Aachen, Aachen, Germany (2000).

[15] F. Halter, T. Tahtouh, C. Mounaim-Rousselle, Combust. Flame 157 (2010) 18251832.

[16] A.P. Kelley, G. Jomaas, C.K. Law, Combust. Flame 156 (2009) 1006-1013.

[17] A.Y. Starikovskii, Proc. Combust. Inst. 30 (2005) 2405-2417.

[18] N. Otsu, Ieee Trans. Syst. Man Cyber. 9 (1979) 62-66.

[19] J. Beeckmann, J. Keppner, T. Glatz, N. Peters, SAE Tech. Paper 2009-01-2656 (2009).

[20] W.H. Green, J.W. Allen, R.W. Ashcraft, G.J. Beran, C.A. Class, C. Gao, C.F. Goldsmith, M.R. Harper, A. Jalan, G.R. Magoon, D.M. Matheu, S.S. Merchant, J.D. Mo, S. Petway, S. Raman, S. Sharma, J. Song, K.M. Van Geem, J. Wen, R.H. West, A. Wong, H. Wong, P.E. Yelvington, J. Yu, RMG - Reaction Mechanism Generator version 3.3, http://rmg. sourceforge.net/ 2011.

[21] S.M. Sarathy, S. Vranckx, K. Yasunaga, M. Mehl, P. Osswald, W.K. Metcalfe, C.K. Westbrook, W.J. Pitz, K. Kohse-Höinghaus, R. X.Fernandes, H.J. Curran, Combust. Flame 159 (2012) 2028-2055.

[22] Chemkin Pro, Reaction Design Inc., San Diego, California 2010.

[23] M.P. Burke, M. Chaos, Y. Ju, F.L. Dryer, S.J. Klippenstein, Int. J. Chem. Kinet. 44 (2012) 444-474.

[24] F.M. Haas, S. Vranckx, M. Chaos, R.X. Fernandes, F.L. Dryer, An updated combustion kinetic model for syngas fuels and C1 oxygenates, Tech. Meeting Eastern states section Combust. Inst., Storrs, Connecticut, U.S.A. 2011.

[25] D. Healy, N.S. Donato, C.J. Aul, E.L. Petersen, C.M. Zinner, G. Bourque, H.J. Curran, Combust. Flame 157 (2010) 1526-1539.

[26] K. Narayanaswamy, G. Blanquart, H. Pitsch, Combust. Flame 157 (2010) 1879-1898.

[27] G. Blanquart, P. Pepiot-Desjardins, H. Pitsch, Combusti. Flame 156 (2009) 588-607.

[28] A.M. El-Nahas, M.V. Navarro, J.M. Simmie, J.W. Bozzelli, H.J. Curran, S. Dooley, W. Metcalfe, J. Phys. Chem. A 111 (2007) 3727-3739.

[29] R. Sumathi, J. Green, Phys. Chem. Chem. Phys. 5 (2003) 3402-3417. 
[30] W.A. Kopp, R.T. Langer, K. Leonhard, Hydrogen Abstraction from N-Butyl Formate by $\mathrm{H}$ and $\mathrm{HO}_{2}$, in preperation 2013.

[31] A. Tarnopolsky, A. Karton, R. Sertchook, D. Vuzman, J.M.L. Martin, J. Phys. Chem. A 112 (2008) 3-8.

[32] S.L. Fischer, F.L. Dryer, H.J. Curran, Int. J. Chem. Kinet. 32 (2000) 713-740.

[33] M. Saeys, M.F. Reyniers, G.B. Marin, V. Van Speybroeck, M. Waroquier, J. Phys. Chem. A 107 (2003) 9147-9159.

[34] J.A. Montgomery, M.J. Frisch, J.W. Ochterski, G.A. Petersson, J. Chem. Phys. 112 (2000) 6532-6542.

[35] M.J. Frisch W. Trucks, H.B. Schlegel, G.E. Scuseria, M.A. Robb, J.R. Cheeseman, J.A. Montgomery, Jr., T. Vreven, K.N. Kudin, J.C. Burant, J.M. Millam, S.S. Iyengar, J. Tomasi, V. Barone, B. Mennucci, M. Cossi, G. Scalmani, N. Rega, G.A. Petersson, H. Nakatsuji, M. Hada, M. Ehara, K. Toyota, R. Fukuda, J. Hasegawa, M. Ishida, T. Nakajima, Y. Honda, O. Kitao, H. Nakai, M. Klene, X. Li, J. E. Knox, H.P. Hratchian, J.B. Cross, V. Bakken, C. Adamo, J. Jaramillo, R. Gomperts, R.E. Stratmann, O. Yazyev, A.J. Austin, R. Cammi, C. Pomelli, J.W. Ochterski, P.Y. Ayala, K. Morokuma, G.A. Voth, P. Salvador, J.J. Dannenberg, V.G. Zakrzewski, S. Dapprich, A.D. Daniels, M.C. Strain, O. Farkas, D.K. Malick, A.D. Rabuck, K. Raghavachari, J.B. Foresman, J.V. Ortiz, Q. Cui, A.G. Baboul, S. Clifford, J. Cioslowski, B.B. Stefanov, G. Liu, A. Liashenko, P. Piskorz, I. Komaromi, R.L. Martin, D.J. Fox, T. Keith, M.A. Al-Laham, C.Y. Peng, A. Nanayakkara, M. Challacombe, P.M.W. Gill, B. Johnson, W. Chen, M.W. Wong, C. Gonzalez, J.A. Pople, Gaussian03, Gaussian Inc., Wallingford CT, 2004.

[36] A. Ghysels, T. Verstraelen, K. Hemelsoet, M. Waroquier, V. Van Speybroeck, J. Chem. Inf. Model. 50 (2010) 1736-1750.

[37] G. Mittal, M. Chaos, C.J. Sung, F.L. Dryer, Fuel Process. Technol. 89 (2008) 12441254.

[38] H. Pitsch, FlameMaster: A C++ computer programm for 0D combustion and 1D laminar flame calculations. 


\section{TABLE HEADERS:}

\section{Tabel 1}

Heat capacity $\left(\mathrm{C}_{\mathrm{p}}\right)$ of butyl formate as a function of temperature

\section{Table 2}

Images of an expending stoichiometric n-butyl formate flame.

\section{Table 3}

Comparison of bond dissociation energies of $n$-butyl formate and methyl butanoate. Units: $\mathrm{kcal} / \mathrm{mol}$

\section{Table 4}

Arrhenius Parameters for n-butyl formate hydrogen abstraction reactions

\section{Table 5}

CBS-QB3 calculated thermodynamic properties of n-butyl formate and its primary radicals. The enthalpy of formation, $\Delta H_{\mathrm{f}}{ }^{298}$, is given in $\mathrm{kcal} \mathrm{mol}^{-1}$, the entropy values, $S_{0}$, and heat capacity values at constant pressure, $C_{\mathrm{p}}$, are in cal $\mathrm{mol}^{-1} \mathrm{~K}^{-1}$.

\section{Table 6}

Shock tube ignition delay time data for stoichiometric n-butyl formate/air mixtures. $\mathrm{P}$ and $\mathrm{T}$ values correspond to the initial post-shock conditions.

\section{Table 7}

RCM ignition delay times and experimental conditions for stoichiometric mixtures of $\mathrm{n}$ butylformate and technical air. The reported pressure and temperature values are the top-deadcentre values. $\mathrm{O}_{2}$ :diluents ratio equals $1: 3.77$ in all cases. 


\section{FIGURE CAPTIONS:}

Figure 1: Cross-sectional schematic view of the Rapid Compression Machine (RCM).

Figure 2: Schematic overview of the experimental setup.

Figure 3: Bond dissociation energies of butyl formate calculated at CBS-QB3 level of theory from the global minima (TG'TC). The values are reported in units of $\mathrm{kcal} / \mathrm{mol}$.

Figure 4: Auto-ignition delay times for stoichiometric mixtures of n-butyl formate and technical air. Kinetic model simulations are depicted which include the influence of the positive pressure gradient observed in the shock tube experiment and the influence of compression and heat loss for the RCM experiments.

Figure 5: Experimental pressure trace, time derivative of the pressure, and the simulation of the full experiment including compression and heat loss for an RCM experiment with compressed pressure and temperature of 19.9 bar and $716 \mathrm{~K}$.

Figure 6: First stage ignition delay times due to cool flame events for intermediate temperature RCM experiments at about 20 bar. Detailed model simulations (var. vol.) have been included for these cool flame events including compression and heat loss. The lines plotted are homogenous simulations (cte. vol.) excluding compression and heat loss influences for both the cool flame and the total ignition time to show the trends predicted by the detailed kinetic mechanism.

Figure 7: Reaction path analysis for n-butyl formate at $20 \%$ fuel consumption, $\Phi=1,750 \mathrm{~K}$, 20 bar.

Figure 8: Cool flame and ignition sensitivities for n-butyl formate oxidation, $\Phi=1,750 \mathrm{~K}$, 20 bar.

Figure 9: Ignition sensitivities for n-butyl formate oxidation, $\Phi=1,1050 \mathrm{~K}, 20$ bar. 
Figure 10: Experimental and numerical laminar burning velocities for initial pressures of 10 bar and initial temperatures of $373 \mathrm{~K}$ for n-butyl formate/air mixtures.

Figure 11: Laminar burning velocity reaction sensitivities for butyl formate/air mixtures at initial pressure and temperature of 10 bar and $373 \mathrm{~K}$ based on the present mechanism for three equivalence ratios, $0.8,1.0$ and 1.2 . 


\begin{tabular}{cccccc}
\hline $\mathrm{T}[\mathrm{K}]$ & $\mathrm{C}_{\mathrm{p}}[\mathrm{J} / \mathrm{mol} \cdot \mathrm{K}]$ & $\mathrm{T}[\mathrm{K}]$ & $\mathrm{C}_{\mathrm{p}}[\mathrm{J} / \mathrm{mol} \cdot \mathrm{K}]$ & $\mathrm{T}[\mathrm{K}]$ & $\mathrm{C}_{\mathrm{p}}[\mathrm{J} / \mathrm{mol} \cdot \mathrm{K}]$ \\
\hline 50 & 7.77 & 400 & 162.6 & 1100 & 308.4 \\
100 & 34.81 & 500 & 194.2 & 1200 & 319.1 \\
150 & 60.06 & 600 & 221.3 & 1300 & 328.3 \\
200 & 83.61 & 700 & 244.6 & 1400 & 336.3 \\
273.15 & 115.2 & 800 & 264.5 & 1500 & 343.3 \\
298.15 & 125.3 & 900 & 281.4 & 1750 & 357.3 \\
300 & 126.0 & 1000 & 296.0 & 2000 & 366.9
\end{tabular}




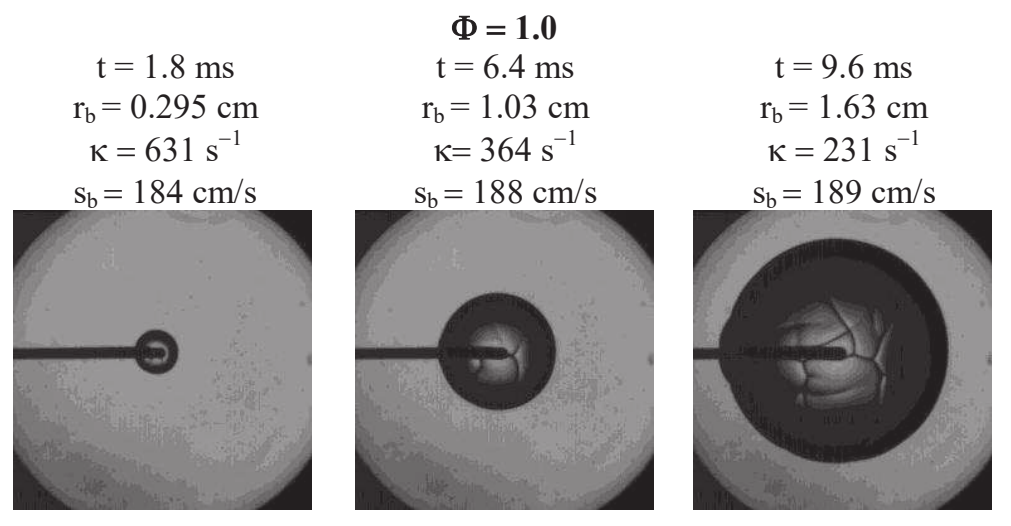




\begin{tabular}{lll}
\hline Bond & BDE n-butyl formate & BDE methyl butanoate \\
\hline $\mathrm{C}-\mathrm{H}$ bonds & & \\
\hline $\mathrm{CH}_{3}-\mathrm{CH}_{2}-\mathrm{CH}_{2}-\mathrm{CH}_{2}-\mathrm{O}-(\mathrm{C}=\mathrm{O}) \ldots \mathrm{H}$ & 95.18 & 94.17 \\
$\mathrm{CH}_{3}-\mathrm{CH}_{2}-\mathrm{CH}_{2}-(\mathrm{H} \ldots \mathrm{CH})-\mathrm{O}-(\mathrm{C}=\mathrm{O}) \mathrm{H}$ & 97.12 & 98.71 \\
$\mathrm{CH}_{3}-\mathrm{CH}_{2}-(\mathrm{H} \ldots \mathrm{CH})-\mathrm{CH}_{2}-\mathrm{O}-(\mathrm{C}=\mathrm{O}) \mathrm{H}$ & 98.86 & 101.1 \\
$\mathrm{CH}_{3}-(\mathrm{H} \ldots \mathrm{CH})-\mathrm{CH}_{2}-\mathrm{CH}_{2}-\mathrm{O}-(\mathrm{C}=\mathrm{O}) \mathrm{H}$ & 97.7 & \\
$\left(\mathrm{H} \ldots \mathrm{CH}_{2}\right)-\mathrm{CH}_{2}-\mathrm{CH}_{2}-\mathrm{CH}-\mathrm{O}-(\mathrm{C}=\mathrm{O}) \mathrm{H}$ & 100.36 & \\
& 100.36 & \\
& 100.66 & \\
\hline $\mathrm{C}-\mathrm{O}$ and C-C bonds & & 93.45 \\
\hline $\mathrm{CH}_{3}-\mathrm{CH}_{2}-\mathrm{CH}_{2}-\mathrm{CH}_{2}-\mathrm{O} \ldots(\mathrm{C}=\mathrm{O}) \mathrm{H}$ & 100.67 & 84.37 \\
$\mathrm{CH}_{3}-\mathrm{CH}_{2}-\mathrm{CH}_{2}-\mathrm{CH}_{2} \ldots \mathrm{O}-(\mathrm{C}=\mathrm{O}) \mathrm{H}$ & 95.32 & 89.15 \\
$\mathrm{CH}_{3}-\mathrm{CH}_{2}-\mathrm{CH}_{2} \ldots \mathrm{CH}_{2}-\mathrm{O}-(\mathrm{C}=\mathrm{O}) \mathrm{H}$ & 90.03 & (both fragments singulet) \\
$\mathrm{CH}_{3}-\mathrm{CH}_{2} \ldots \mathrm{CH}_{2}-\mathrm{CH}_{2}-\mathrm{O}-(\mathrm{C}=\mathrm{O}) \mathrm{H}$ & 89.04 & \\
$\mathrm{CH}_{3} \ldots \mathrm{CH}_{2}-\mathrm{CH}_{2}-\mathrm{CH}_{2}-\mathrm{O}-(\mathrm{C}=\mathrm{O}) \mathrm{H}$ & 88.66 & 221.79 \\
$\mathrm{CH}_{3}-\mathrm{CH}_{2}-\mathrm{CH}_{2}-\mathrm{CH}_{2}-\mathrm{O}-(\mathrm{C} \ldots \mathrm{O}) \mathrm{H}$ & 201.66 & \\
$\mathrm{CH}_{3}-\mathrm{CH}_{2}-\mathrm{CH}_{2}-\mathrm{CH}_{2}-\mathrm{O}-(\mathrm{C} \ldots \mathrm{O}) \mathrm{H}$ & & \\
\hline & & \\
& &
\end{tabular}




\begin{tabular}{lllll}
\hline Reaction & $\mathrm{A}\left(\mathrm{cm}^{3} \mathrm{~mol}^{-1} \mathrm{~s}^{-1}\right)$ & $n$ & $\mathrm{E}_{\mathrm{A}}(\mathrm{cal} \mathrm{mol}$ \\
$\mathrm{C}_{4} \mathrm{H}_{9} \mathrm{OCHO}+\mathrm{OH}=\mathrm{C}_{4} \mathrm{H}_{9} \mathrm{OCO}+\mathrm{H}_{2} \mathrm{O}$ & $2.33 \mathrm{E}+07$ & 1.60 & $-3.50 \mathrm{E}+01$ & {$[6]$} \\
$\mathrm{C}_{4} \mathrm{H}_{9} \mathrm{OCHO}+\mathrm{OH}=\alpha-\mathrm{C}_{4} \mathrm{H}_{8} \mathrm{OCHO}+\mathrm{H}_{2} \mathrm{O}$ & $1.16 \mathrm{E}+07$ & 1.60 & $-3.50 \mathrm{E}+01$ & {$[6]$} \\
$\mathrm{C}_{4} \mathrm{H}_{9} \mathrm{OCHO}+\mathrm{OH}=\beta-\mathrm{C}_{4} \mathrm{H}_{8} \mathrm{OCHO}+\mathrm{H}_{2} \mathrm{O}$ & $7.00 \mathrm{E}+09$ & 1.00 & $1.59 \mathrm{E}+03$ & {$[6]$} \\
$\mathrm{C}_{4} \mathrm{H}_{9} \mathrm{OCHO}+\mathrm{OH}=\gamma-\mathrm{C}_{4} \mathrm{H}_{8} \mathrm{OCHO}+\mathrm{H}_{2} \mathrm{O}$ & $1.14 \mathrm{E}+03$ & 2.87 & $-2.93 \mathrm{E}+03$ & {$[21]$} \\
$\mathrm{C}_{4} \mathrm{H}_{9} \mathrm{OCHO}+\mathrm{OH}=\delta-\mathrm{C}_{4} \mathrm{H}_{8} \mathrm{OCHO}+\mathrm{H}_{2} \mathrm{O}$ & $5.28 \mathrm{E}+09$ & 0.97 & $1.59 \mathrm{E}+03$ & {$[21]$} \\
$\mathrm{C}_{4} \mathrm{H}_{9} \mathrm{OCHO}+\mathrm{HO}_{2}=\mathrm{C}_{4} \mathrm{H}_{9} \mathrm{OCO}+\mathrm{H}_{2} \mathrm{O}_{2}$ & $1.39 \mathrm{E}-01$ & 4.21 & $1.30 \mathrm{E}+04$ & {$[30]$} \\
$\mathrm{C}_{4} \mathrm{H}_{9} \mathrm{OCHO}+\mathrm{HO}_{2}=\alpha-\mathrm{C}_{4} \mathrm{H}_{8} \mathrm{OCHO}+\mathrm{H}_{2} \mathrm{O}_{2}$ & $1.74 \mathrm{E}-03$ & 4.54 & $1.19 \mathrm{E}+04$ & {$[30]$} \\
$\mathrm{C}_{4} \mathrm{H}_{9} \mathrm{OCHO}+\mathrm{HO}_{2}=\beta-\mathrm{C}_{4} \mathrm{H}_{8} \mathrm{OCHO}+\mathrm{H}_{2} \mathrm{O}_{2}$ & $4.68 \mathrm{E}-02$ & 4.35 & $1.35 \mathrm{E}+04$ & {$[30]$} \\
$\mathrm{C}_{4} \mathrm{H}_{9} \mathrm{OCHO}+\mathrm{HO}_{2}=\gamma-\mathrm{C}_{4} \mathrm{H}_{8} \mathrm{OCHO}+\mathrm{H}_{2} \mathrm{O}_{2}$ & $1.31 \mathrm{E}-04$ & 4.60 & $1.02 \mathrm{E}+04$ & {$[30]$} \\
$\mathrm{C}_{4} \mathrm{H}_{9} \mathrm{OCHO}+\mathrm{HO} \mathrm{O}_{2}=\delta-\mathrm{C}_{4} \mathrm{H}_{8} \mathrm{OCHO}+\mathrm{H}_{2} \mathrm{O}_{2}$ & $7.05 \mathrm{E}-02$ & 4.30 & $1.50 \mathrm{E}+04$ & {$[30]$} \\
$\mathrm{C}_{4} \mathrm{H}_{9} \mathrm{OCHO}+\mathrm{H}=\mathrm{C} \mathrm{H}_{9} \mathrm{OCO}+\mathrm{H}_{2}$ & $7.53 \mathrm{E}+05$ & 2.39 & $6.75 \mathrm{E}+03$ & {$[30]$} \\
$\mathrm{C}_{4} \mathrm{H}_{9} \mathrm{OCHO}+\mathrm{H}=\alpha-\mathrm{C}_{4} \mathrm{H}_{8} \mathrm{OCHO}+\mathrm{H}_{2}$ & $1.06 \mathrm{E}+06$ & 2.35 & $6.25 \mathrm{E}+03$ & {$[30]$} \\
$\mathrm{C}_{4} \mathrm{H}_{9} \mathrm{OCHO}+\mathrm{H}=\beta-\mathrm{C}_{4} \mathrm{H}_{8} \mathrm{OCHO}+\mathrm{H}_{2}$ & $9.04 \mathrm{E}+06$ & 2.13 & $7.29 \mathrm{E}+03$ & {$[30]$} \\
$\mathrm{C}_{4} \mathrm{H}_{9} \mathrm{OCHO}+\mathrm{H}=\gamma-\mathrm{C}_{4} \mathrm{H}_{8} \mathrm{OCHO}+\mathrm{H}_{2}$ & $6.14 \mathrm{E}+05$ & 2.46 & $5.74 \mathrm{E}+03$ & {$[30]$} \\
$\mathrm{C}_{4} \mathrm{H}_{9} \mathrm{OCHO}+\mathrm{H}=\delta \mathrm{C}_{4} \mathrm{H}_{8} \mathrm{OCHO}+\mathrm{H}_{2}$ & $1.15 \mathrm{E}+06$ & 2.43 & $8.09 \mathrm{E}+03$ & {$[30]$}
\end{tabular}




\begin{tabular}{lllllll}
\hline Species & $\Delta H_{\mathrm{f}}{ }^{298}$ & $S_{0}$ & $C_{\mathrm{p}}{ }^{500}$ & $C_{\mathrm{p}}{ }^{1000}$ & $C_{\mathrm{p}}{ }^{1500}$ & $C_{\mathrm{p}}{ }^{2000}$ \\
\hline $\begin{array}{l}n \text {-butyl for- } \\
\text { mate }\end{array}$ & -104.47 & 91.1 & 46.0 & 72.2 & 81.7 & 87.7 \\
$\begin{array}{l}\alpha \text {-butyl for- } \\
\text { mate radical }\end{array}$ & -57.82 & 93.0 & 45.5 & 69.0 & 77.3 & 82.7 \\
$\begin{array}{l}\beta \text {-butyl for- } \\
\text { mate radical }\end{array}$ & -55.98 & 95.8 & 45.4 & 69.0 & 77.3 & 82.7 \\
$\begin{array}{l}\gamma \text {-butyl for- } \\
\text { mate radical }\end{array}$ & -57.13 & 94.8 & 45.4 & 69.1 & 77.4 & 82.8 \\
$\begin{array}{l}\delta \text {-butyl for- } \\
\text { mate radical }\end{array}$ & -54.51 & 94.0 & 45.7 & 69.2 & 77.4 & 82.7 \\
$\begin{array}{l}n \text {-butyl for- } \\
\text { myl radical }\end{array}$ & -56.93 & 92.5 & 44.6 & 68.6 & 77.1 & 82.6 \\
\hline
\end{tabular}




\begin{tabular}{lll}
\hline $\mathrm{P}($ bar $)$ & $\mathrm{T}(\mathrm{K})$ & $\mathrm{t}_{\text {ign }}(\mathrm{ms})$ \\
\hline 17.5 & 846 & 5.32 \\
17.9 & 854 & 4.93 \\
17.3 & 856 & 5.2 \\
19.6 & 935 & 2.85 \\
18 & 992 & 1.78 \\
18.6 & 1050 & 1.05 \\
18.2 & 1077 & 0.77 \\
21.1 & 1154 & 0.21 \\
18.9 & 1205 & 0.11 \\
82 & 780 & 1.33 \\
87.2 & 820 & 0.95 \\
91 & 855 & 0.66 \\
90 & 868 & 0.64 \\
81.3 & 884 & 0.64 \\
92.4 & 901 & 0.53 \\
93.1 & 901 & 0.53 \\
92.9 & 911 & 0.52 \\
91.6 & 942 & 0.48 \\
94.1 & 972 & 0.40 \\
81.4 & 1000 & 0.36 \\
94.2 & 1051 & 0.20 \\
84 & 1056 & 0.22 \\
83.7 & 1065 & 0.19 \\
94.1 & 1107 & 0.10 \\
92.1 & 1183 & 0.036 \\
\hline & &
\end{tabular}




\begin{tabular}{|c|c|c|c|c|c|c|c|}
\hline $\begin{array}{c}P_{i} \\
\text { (bar) }\end{array}$ & $T_{i}(\mathrm{~K})$ & P (bar) & $\mathrm{T}(\mathrm{K})$ & $\mathrm{t}_{\mathrm{ign}}(\mathrm{ms})$ & $\mathrm{t}_{\text {cool flame }}(\mathrm{ms})$ & $\begin{array}{c}\text { Diluent } \\
\text { composition } \\
\left(\mathrm{Ar}: \mathrm{N}_{2}\right)\end{array}$ & $\begin{array}{l}\text { Compres- } \\
\text { sion ratio }\end{array}$ \\
\hline 0.87 & 303 & 19.8 & 646 & 60.9 & & $0: 1$ & 14.4 \\
\hline 0.83 & 303 & 21.0 & 661 & 35.4 & & $0: 1$ & 16.1 \\
\hline 0.71 & 303 & 19.7 & 674 & 25.8 & & $0: 1$ & 18.2 \\
\hline 0.6 & 289 & 20.7 & 679 & 18.4 & & $0: 1$ & 22.9 \\
\hline 0.61 & 293 & 20.0 & 680 & 26.6 & & $0: 1$ & 22.9 \\
\hline 0.6 & 289 & 21.0 & 681 & 16.3 & & $0: 1$ & 22.9 \\
\hline 0.61 & 294 & 20.0 & 682 & 22.4 & & $0: 1$ & 22.9 \\
\hline 0.61 & 294 & 20.3 & 684 & 19.7 & & $0: 1$ & 22.9 \\
\hline 0.61 & 294 & 20.6 & 686 & 19.4 & & $0: 1$ & 22.9 \\
\hline 0.59 & 289 & 20.0 & 688 & 18.2 & & $0.1: 0.9$ & 22.9 \\
\hline 0.61 & 303 & 20.1 & 700 & 15.1 & & $0: 1$ & 22.9 \\
\hline 0.48 & 293 & 19.3 & 711 & 12.1 & 9.0 & $0: 1$ & 31 \\
\hline 0.5 & 291 & 21.0 & 714 & 10.7 & 7.0 & $0: 1$ & 31 \\
\hline 0.48 & 292 & 20.0 & 715 & 13.1 & 8.8 & $0: 1$ & 31 \\
\hline 0.48 & 293 & 19.9 & 716 & 11.2 & 7.2 & $0: 1$ & 31 \\
\hline 0.5 & 291 & 20.5 & 718 & 13.3 & 7.3 & $0: 1$ & 31 \\
\hline 0.4 & 291 & 16.7 & 718 & 15.2 & 7.0 & $0.05: 0.95$ & 31 \\
\hline 0.4 & 291 & 16.8 & 725 & 14.2 & 6.0 & 0.1:0.9 & 31 \\
\hline 0.43 & 306 & 16.4 & 730 & 11.2 & 6.8 & $0: 1$ & 31 \\
\hline 0.4 & 291 & 16.8 & 732 & 11.8 & 7.0 & $0.15: 0.85$ & 31 \\
\hline 0.4 & 291 & 17.2 & 742 & 10.4 & 4.0 & $0.2: 0.8$ & 31 \\
\hline 0.4 & 291 & 17.2 & 748 & 8.5 & 4.0 & $0.25: 0.75$ & 31 \\
\hline 0.4 & 291 & 17.4 & 757 & 7.3 & 3.0 & $0.3: 0.7$ & 31 \\
\hline 0.4 & 291 & 17.8 & 775 & 7.6 & & $0.4: 0.6$ & 31 \\
\hline 0.4 & 290 & 18.1 & 791 & 7.8 & & $0.5: 0.5$ & 31 \\
\hline 0.4 & 290 & 19.0 & 816 & 7.7 & & $0.6: 0.4$ & 31 \\
\hline 0.4 & 291 & 19.2 & 839 & 6.4 & & $0.7: 0.3$ & 31 \\
\hline 0.4 & 290 & 19.2 & 847 & 7.2 & & $0.75: 0.25$ & 31 \\
\hline 0.4 & 291 & 19.5 & 861 & 4.7 & & $0.8: 0.2$ & 31 \\
\hline 0.5 & 307 & 19.9 & 738 & 6.2 & 2.5 & $0: 1$ & 31 \\
\hline 0.5 & 347 & 19.7 & 818 & 4.0 & & $0: 1$ & 31 \\
\hline
\end{tabular}




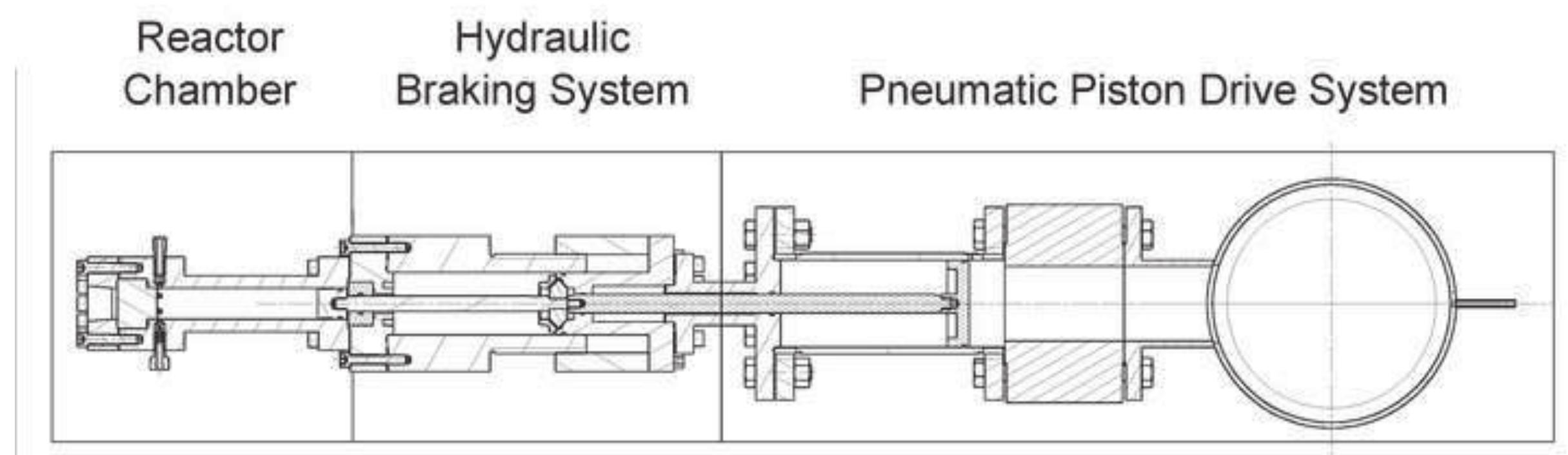




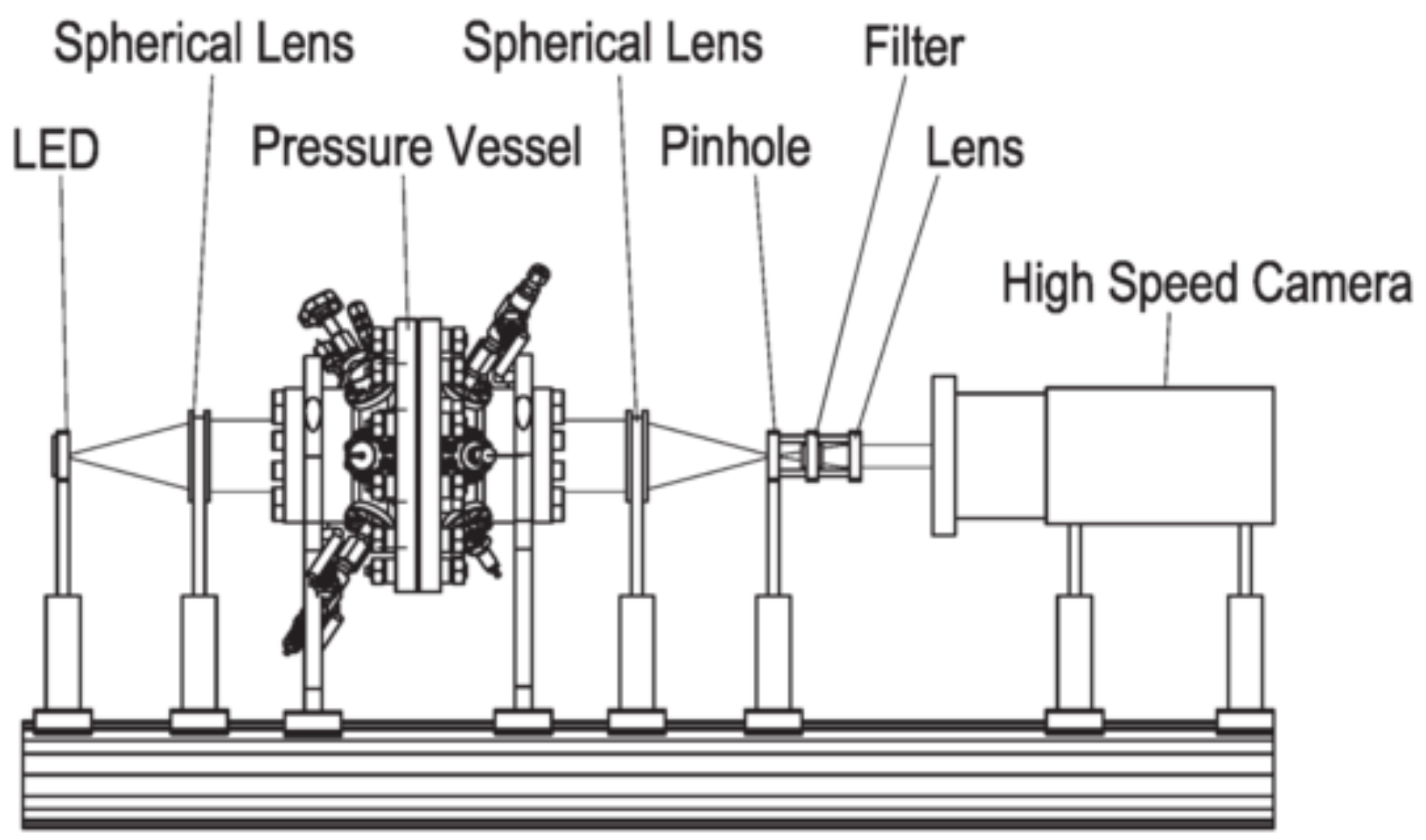




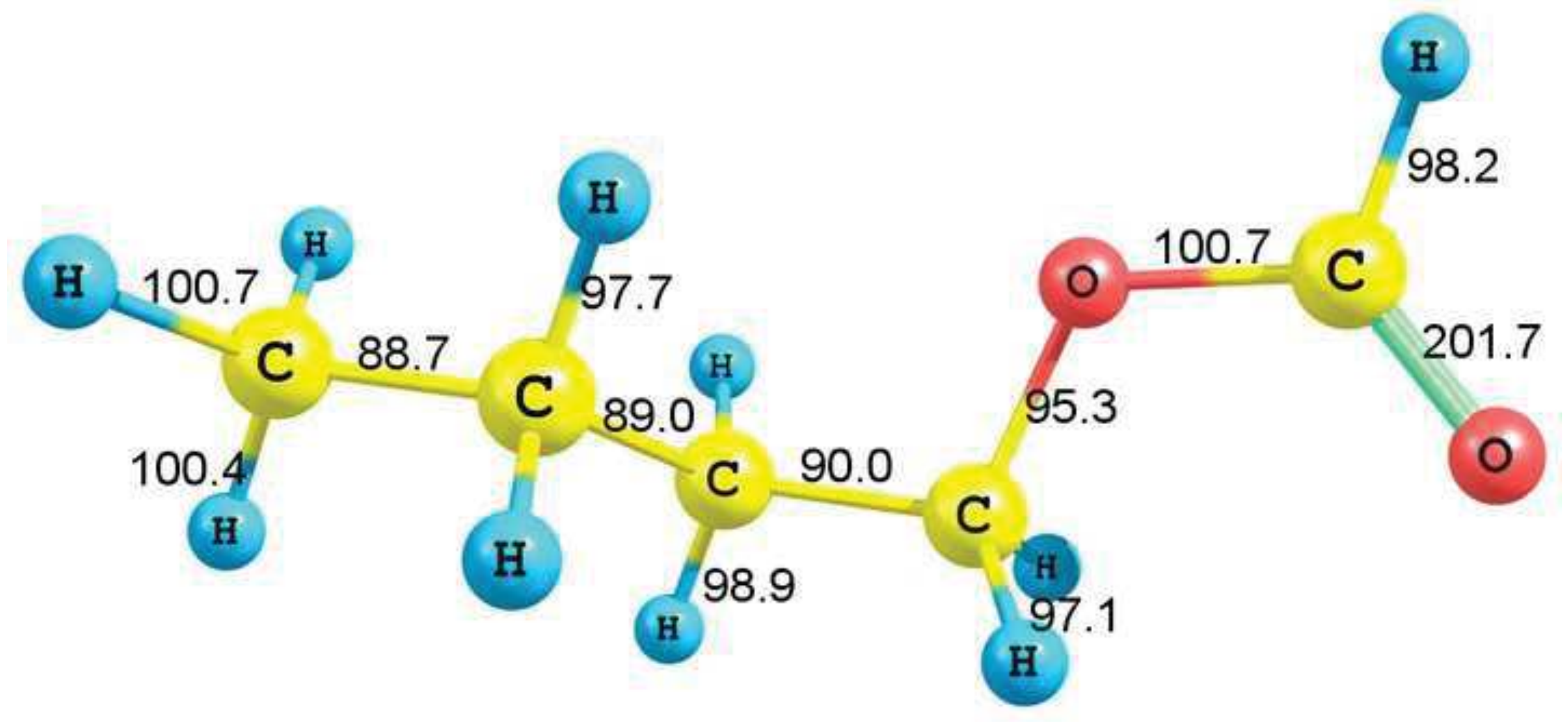




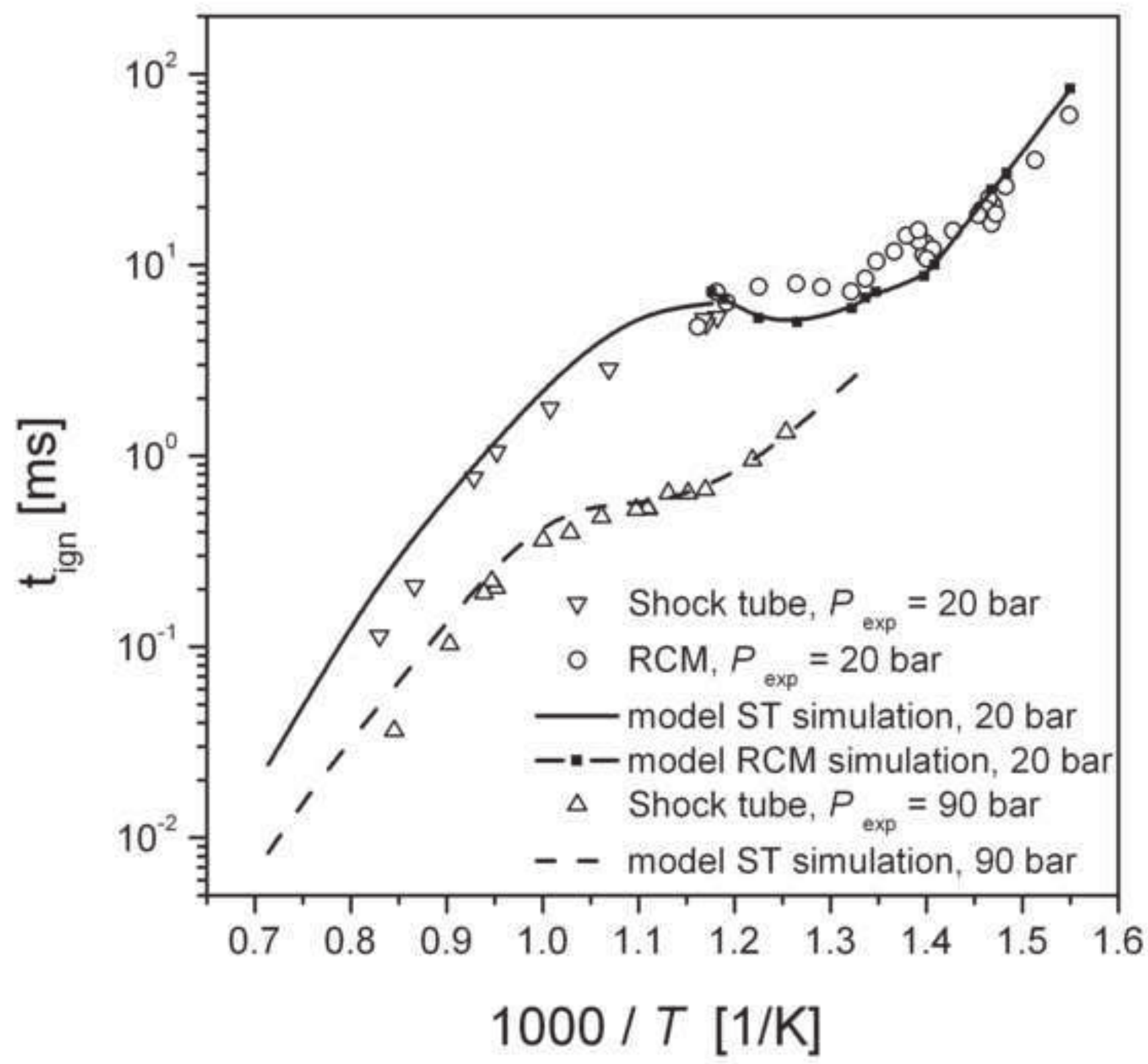




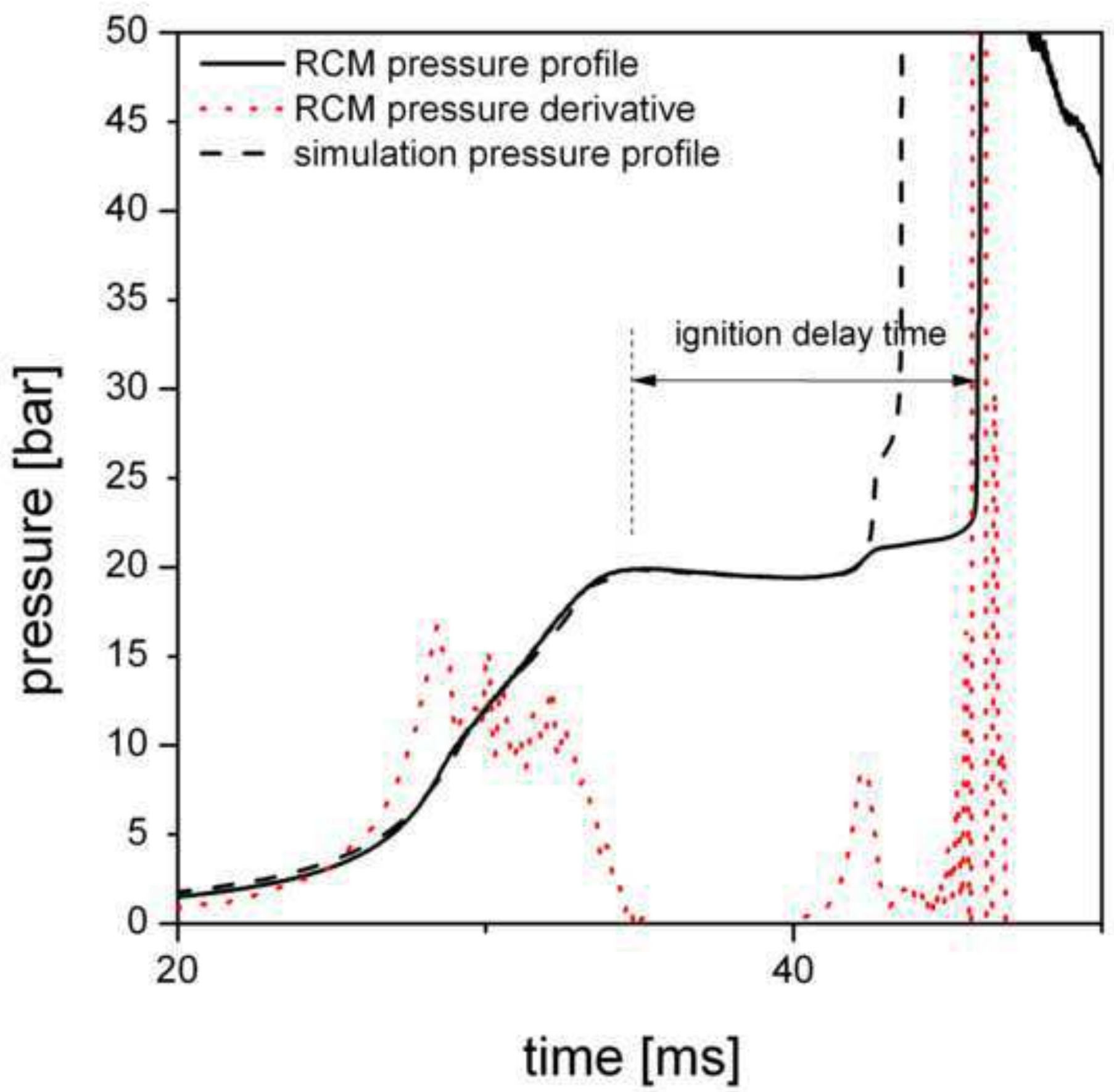




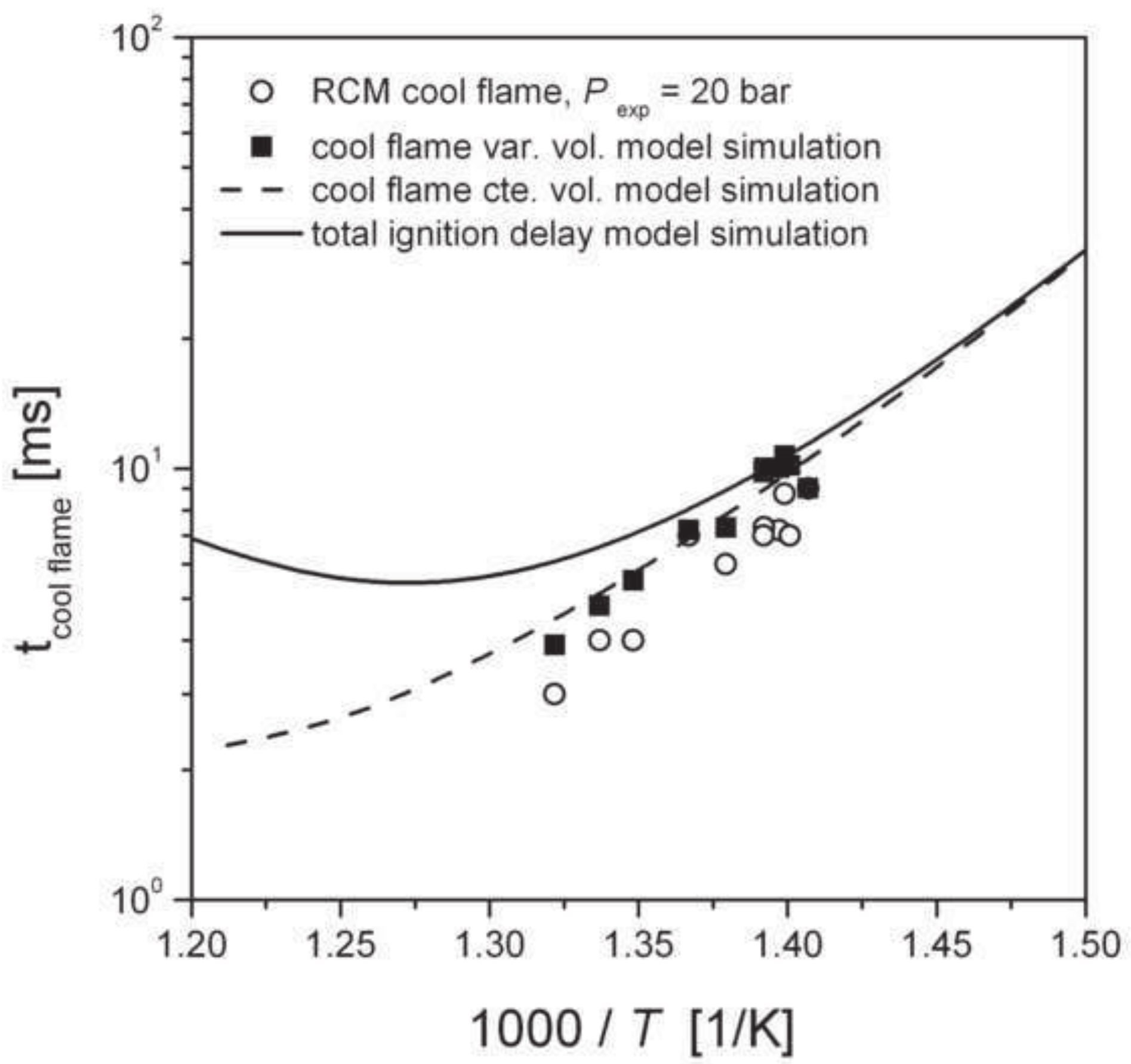




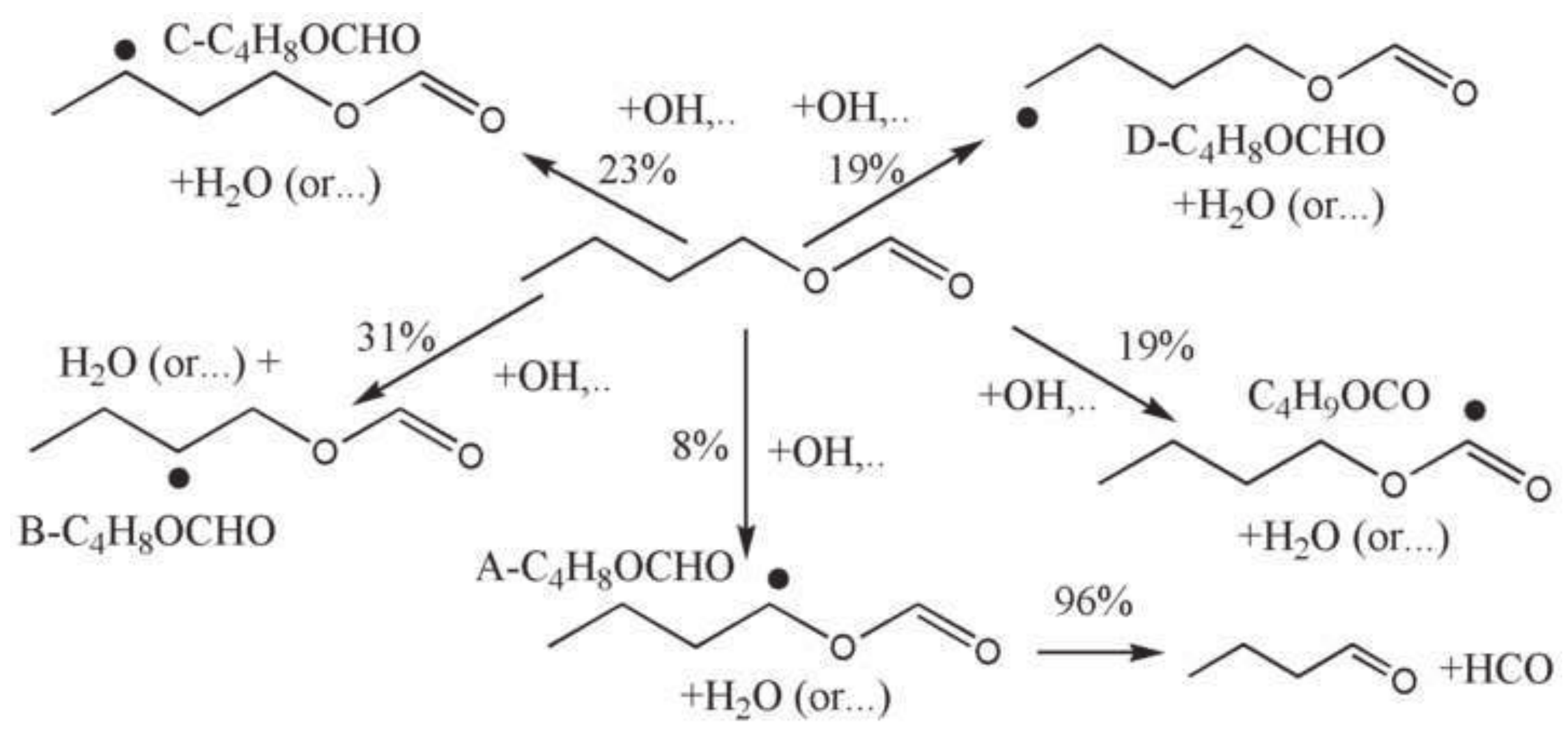




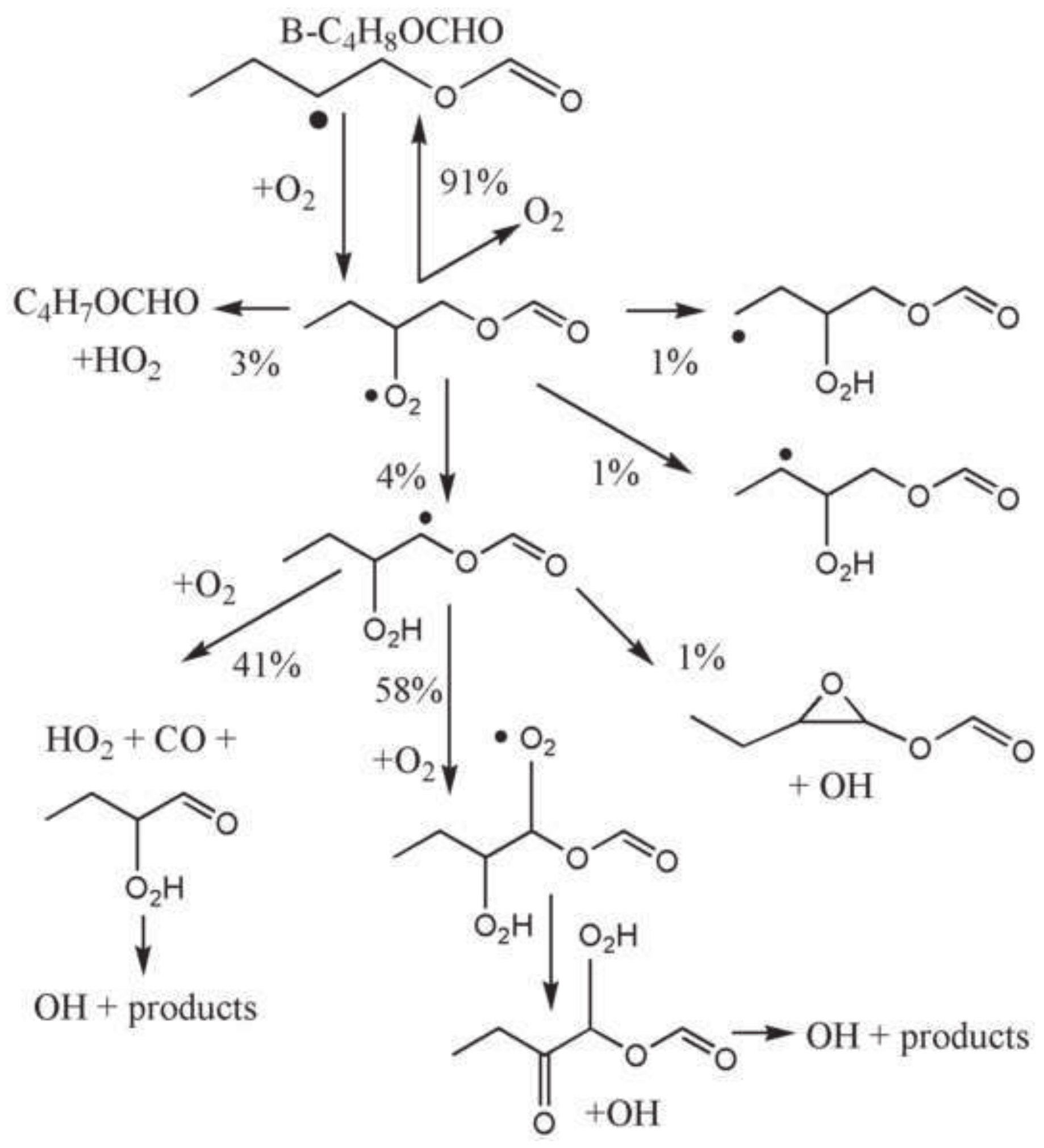




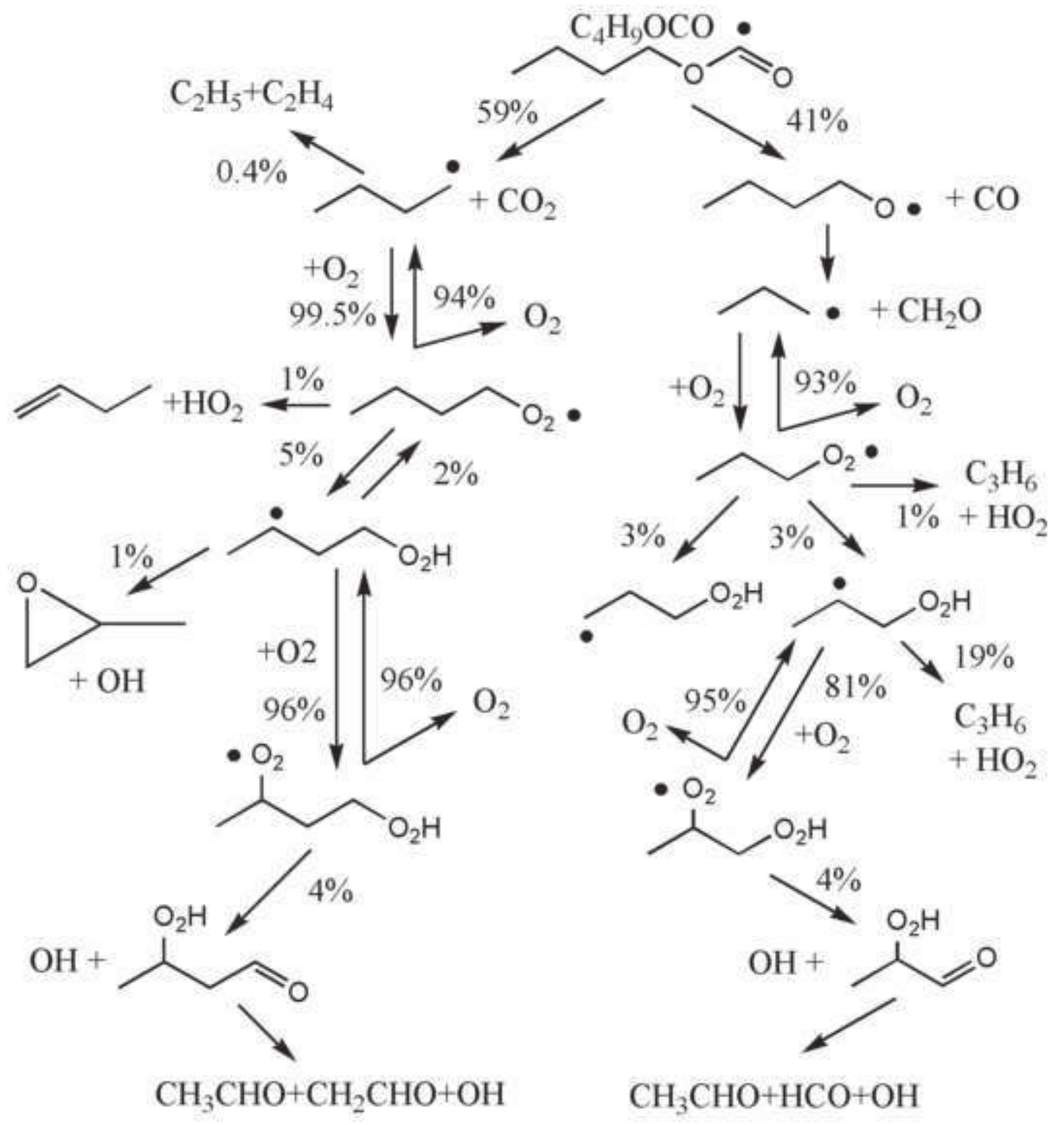




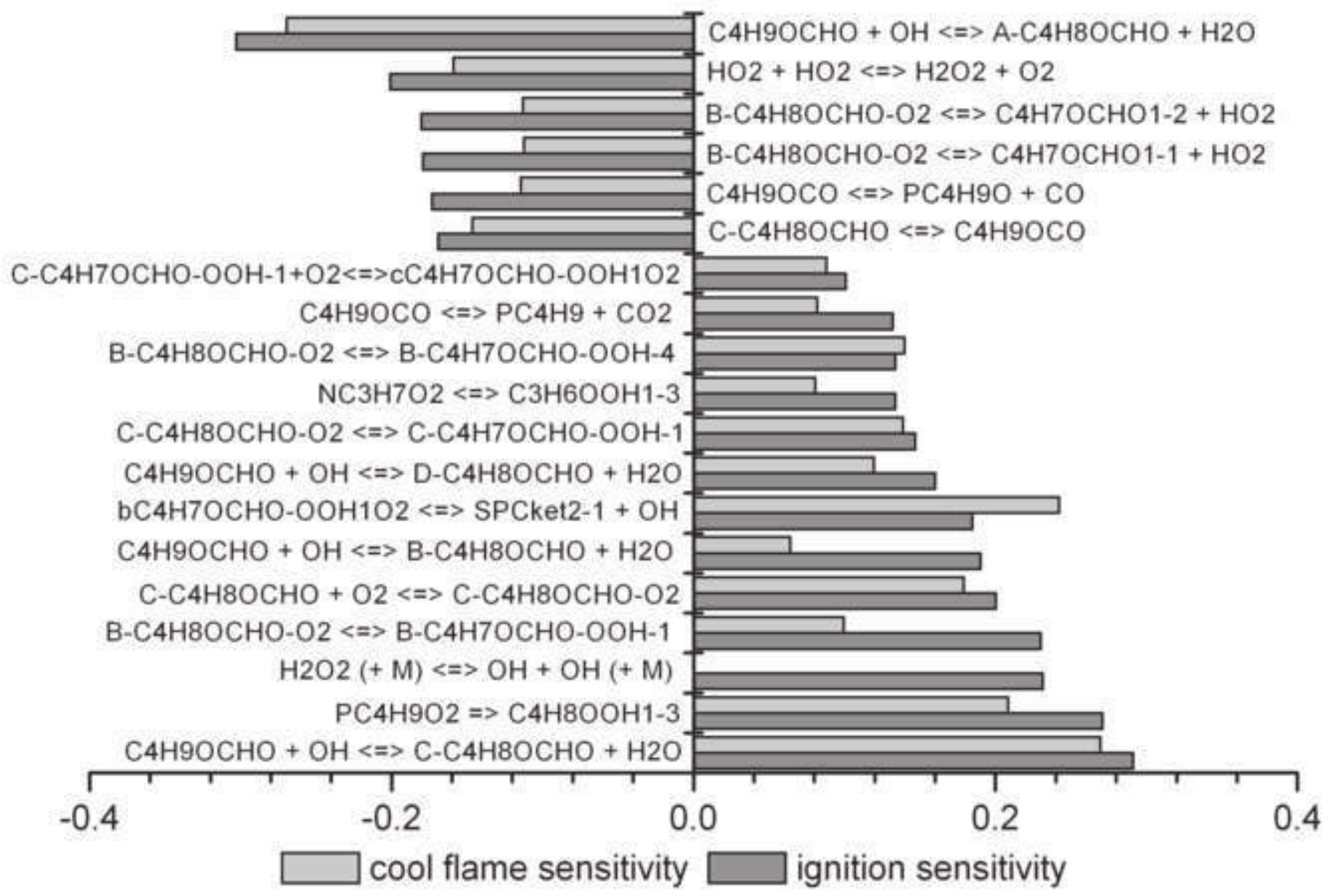




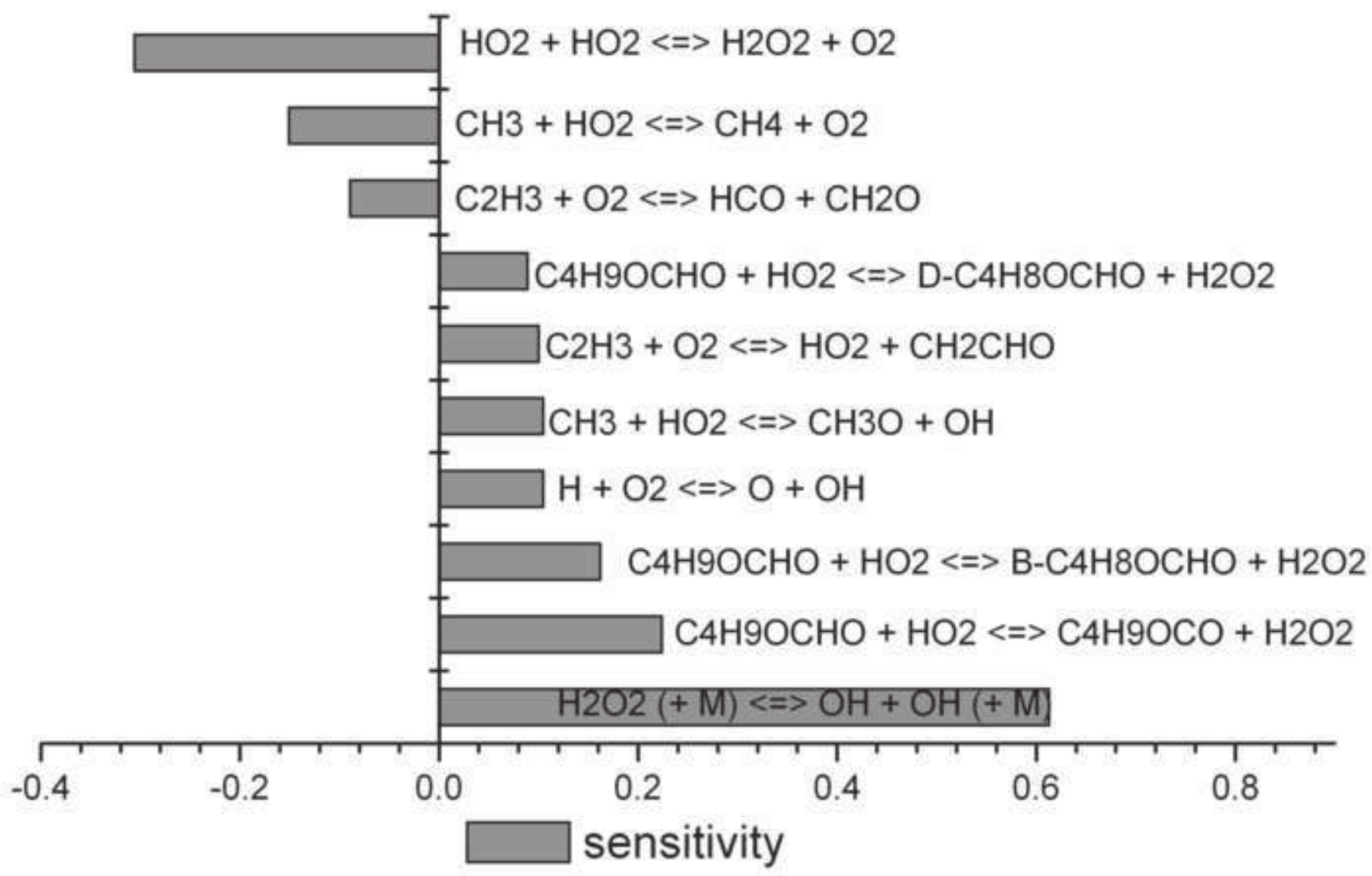




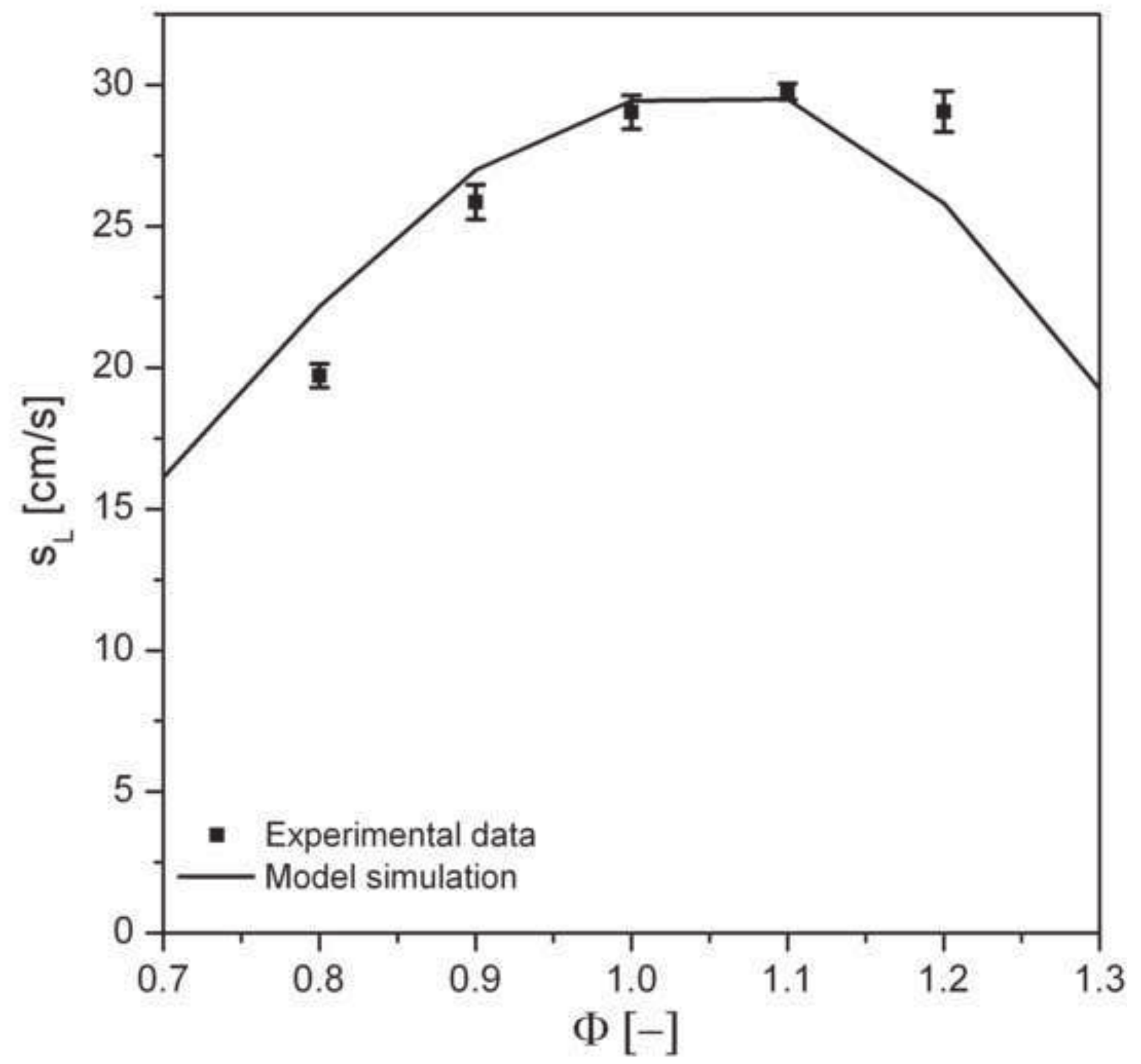




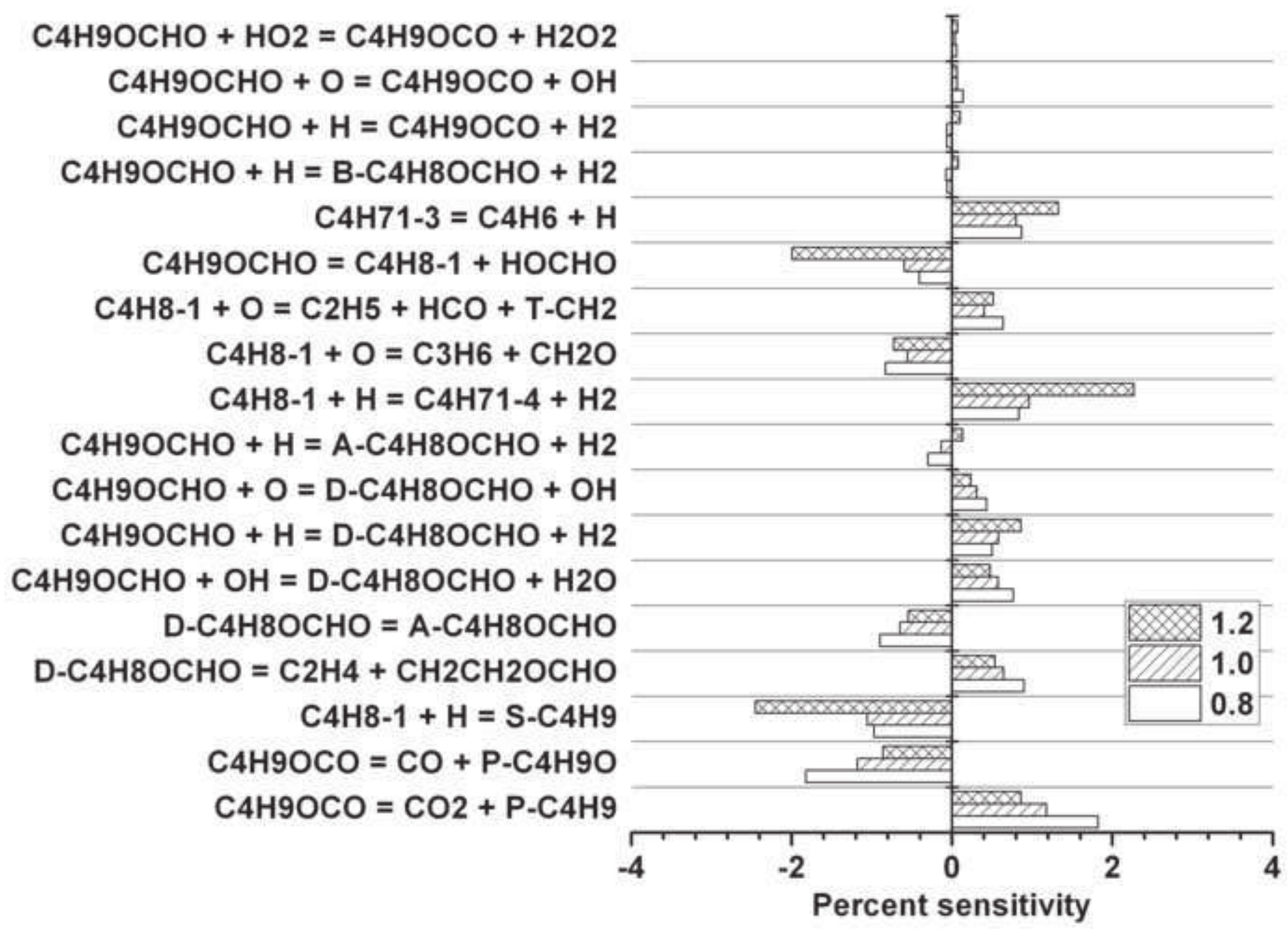

